\title{
FARMERS KNOWLEDGE OF TECHNICAL RECOMMENDATIONS RELATED TO CULTIVATION AND PRODUCTION OF FABA BEAN IN NEWLY RECLAIMED AREA AND OTHER OLD AREA IN KAFR EL-SHEIKH GOVERNORAT
}

Zedan, E. A. A

Res. Inst. of Agric. Extension and Rural Development, Agric. Res. Center, Ministry of Agric. and Land Rreclamation

$$
\begin{aligned}
& \text { معسارف الـزراع بالتوصـيات الفتيـة لزراعـة وإنتـاج الفـول البلـدي بمنطقـة حديثة } \\
& \text { الاستصلاح وأخري قديمة بمحافظة كفر الثيخ الثيخ }
\end{aligned}
$$

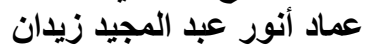

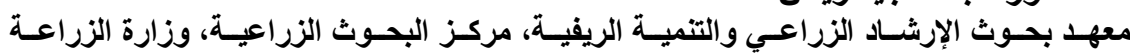

$$
\begin{aligned}
& \text { واستصلاح الأراضي }
\end{aligned}
$$

\section{الملخص}

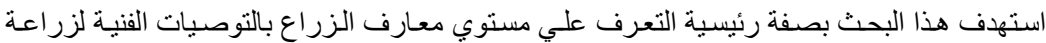

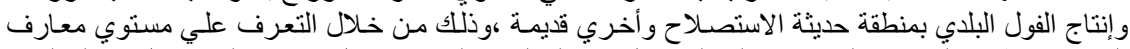

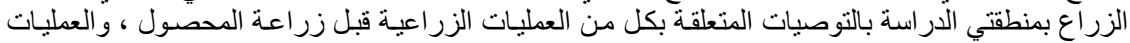

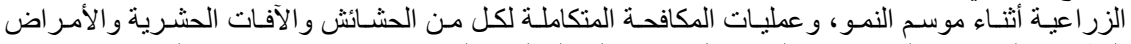

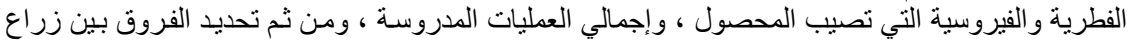

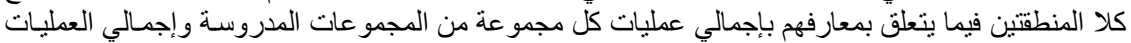

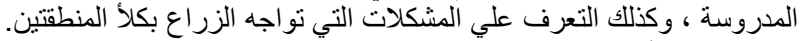

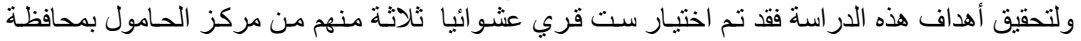

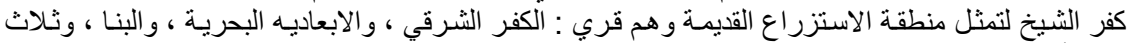

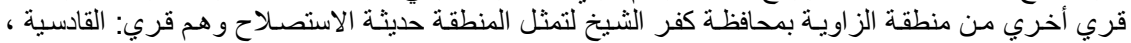

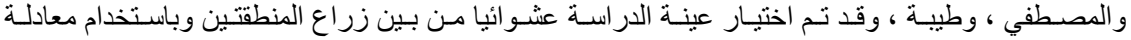

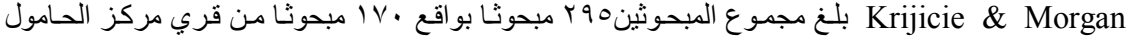

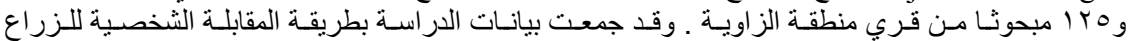

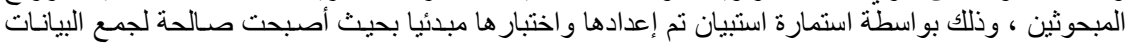

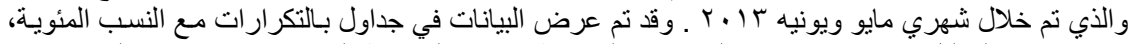

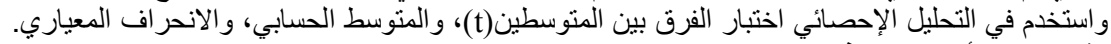

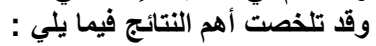

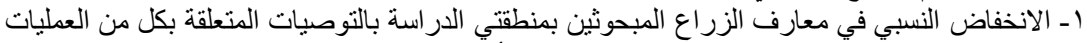

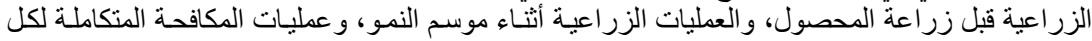

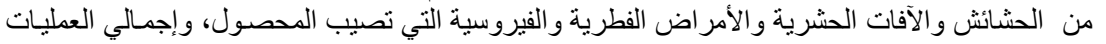

$$
\text { الب المدروسة. }
$$

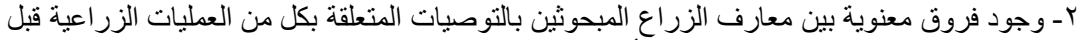

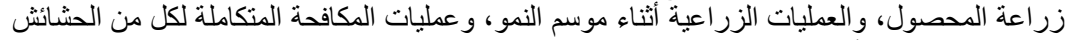

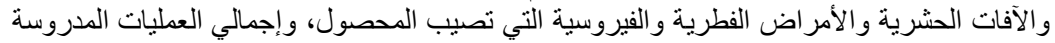
بمنطقي الدراسة.

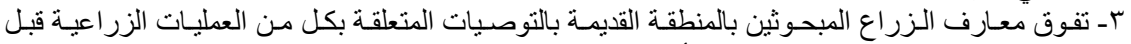

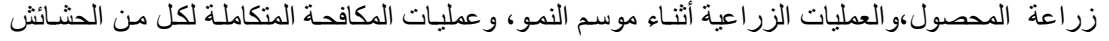


و الآفات الحشرية والأمر اض الفطرية والفيروسية التي تصيب المحصول، وإجمالي العمليات المدروسـة عن

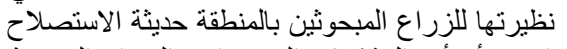

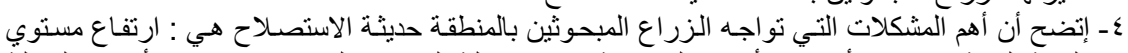

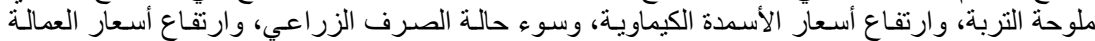

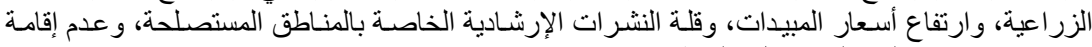

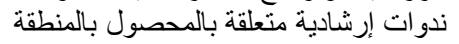

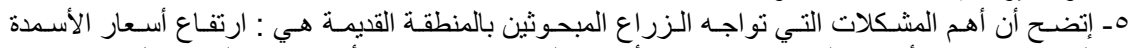

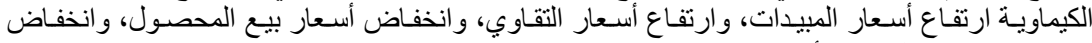

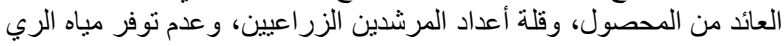

\section{المقدمة و المثكلة البحثية}

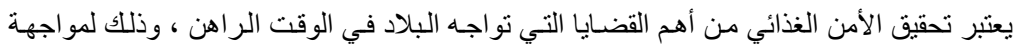

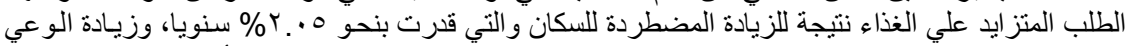

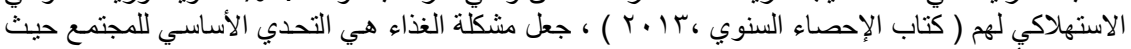

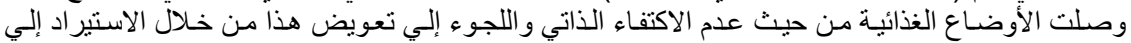

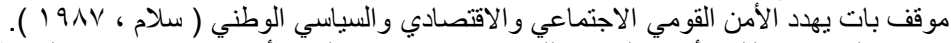

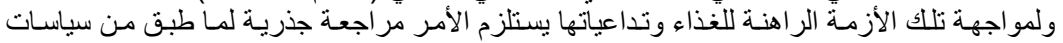

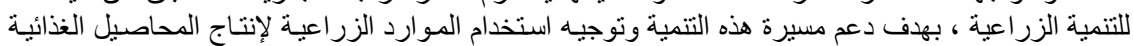

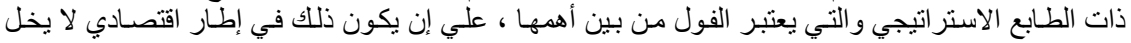

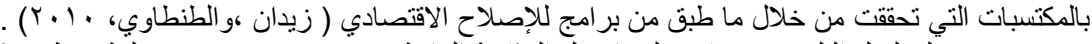

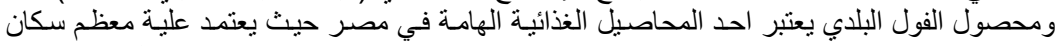

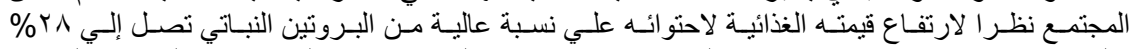

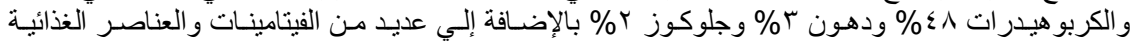

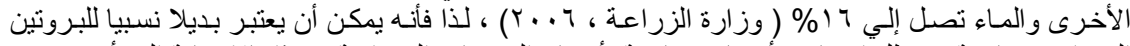

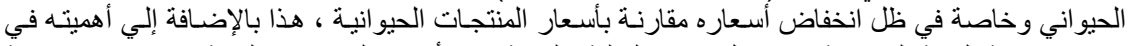

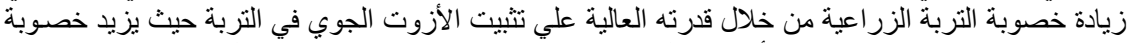

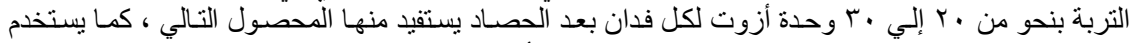

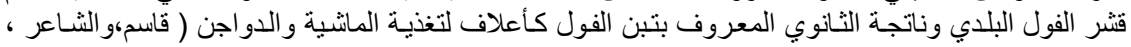

. $(r \cdot 1$.

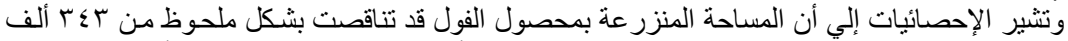

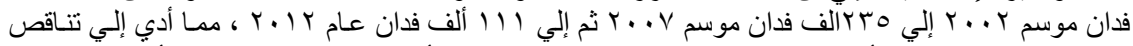

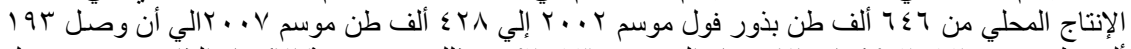

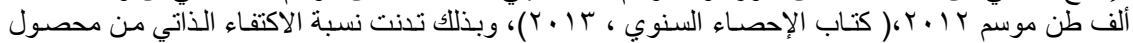

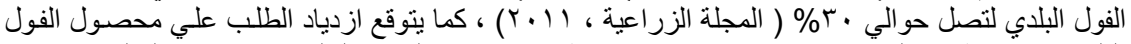

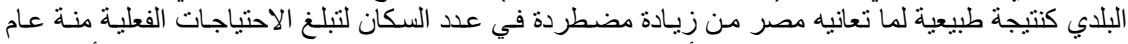

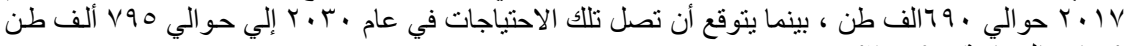

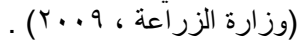

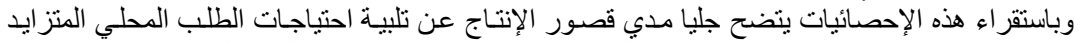

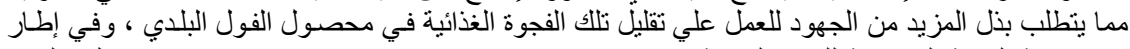

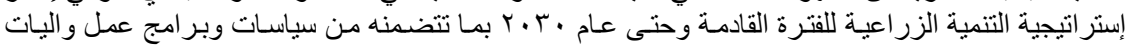

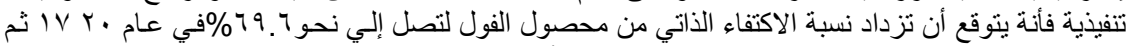

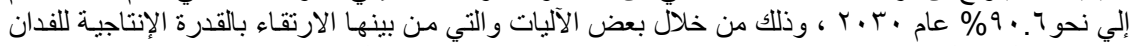

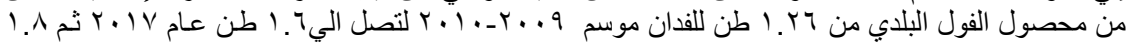

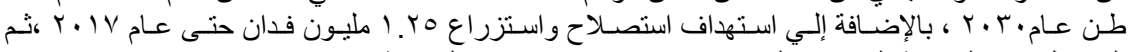

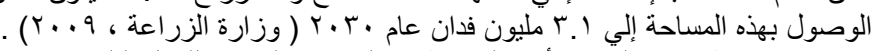

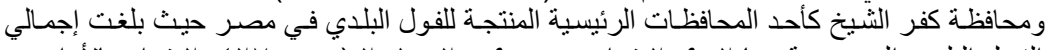

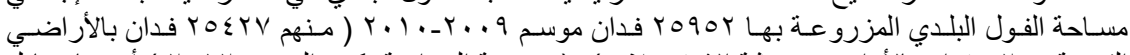

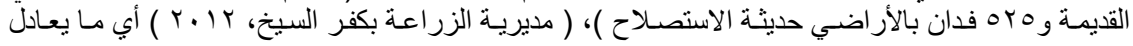




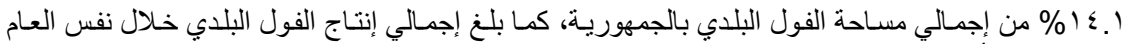

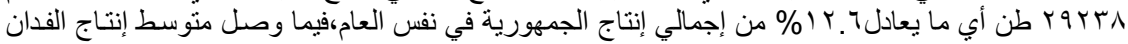

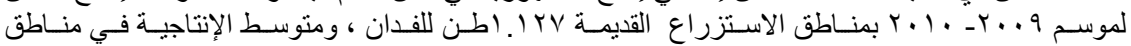

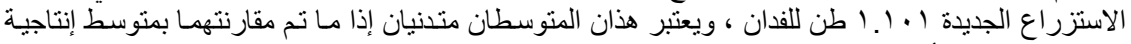

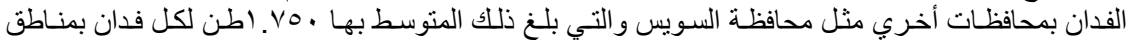

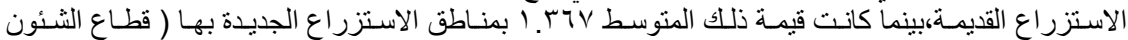

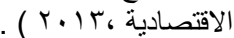

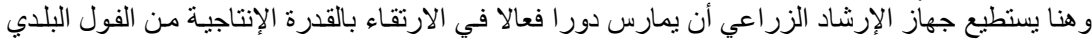

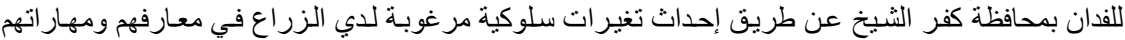

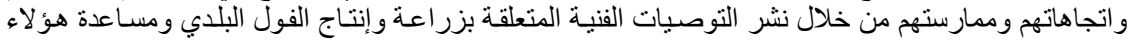

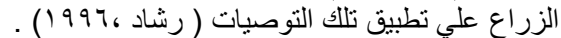

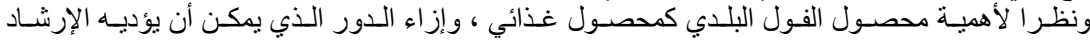

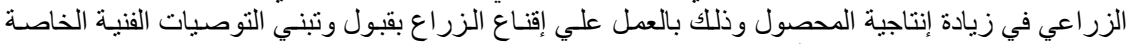

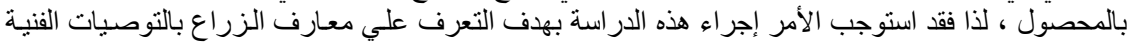

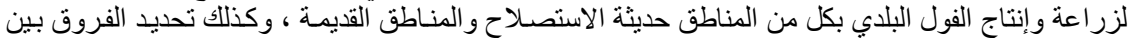

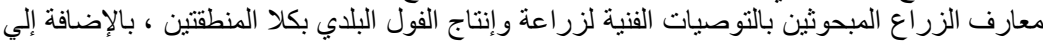

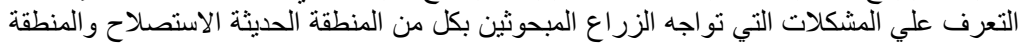

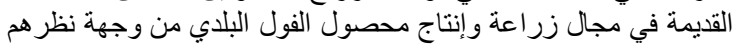

\section{أهداف البحث}

إتساقاً مع مقدمة البحث و إنطلاقةاً من المشكلة البحثية:

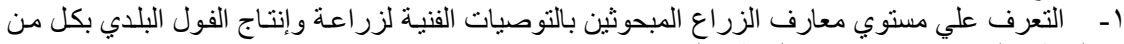

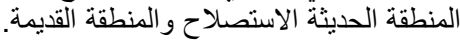

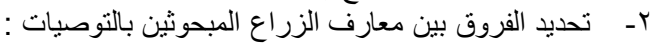

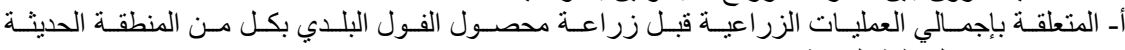
الاستصلاح و المنطقة القديمة.

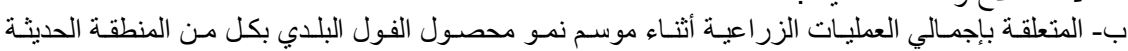
الاستصلاح و المنطقة القديمة.

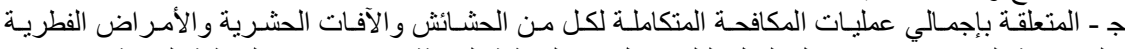

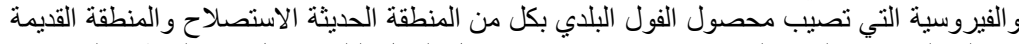

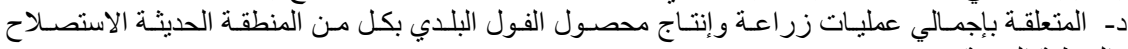

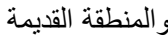
بـ التعرف علي المشكلات التي تواجه الزراع المبحوثين بكل من المنطقة الحديثة الاستصلاح و المنطقة

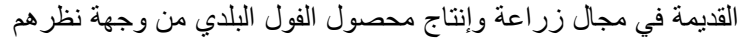




\section{الفروض البحثية}

لتحقيق هدف الدراسة الثاني بفروعه الأربعة تم صياغة الفروض البحثية التالية :

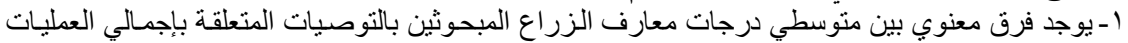

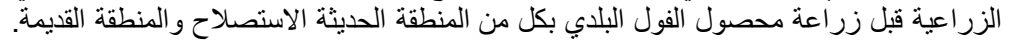

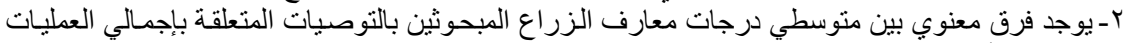

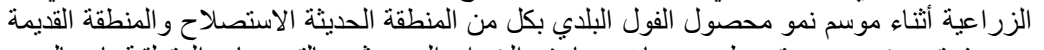

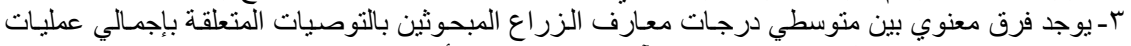

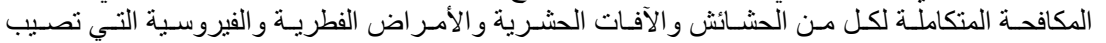

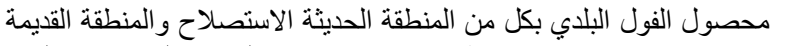

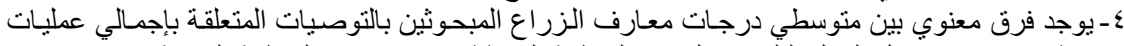

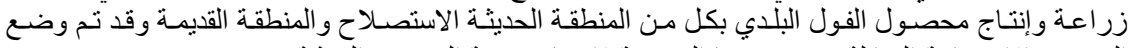

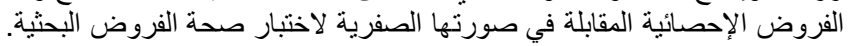

\section{الأسلوب البحثي}

منطقة البحث

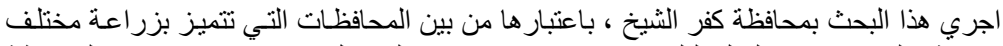

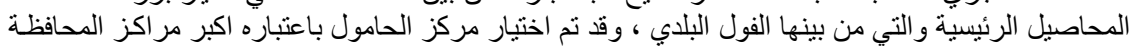

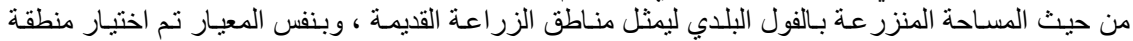

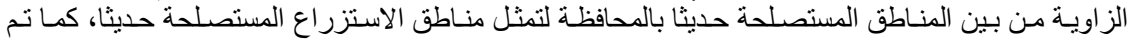

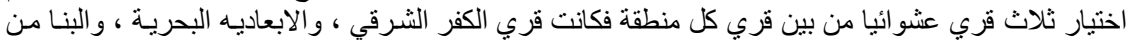

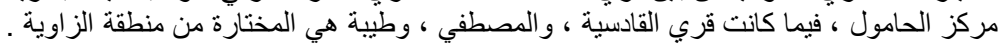

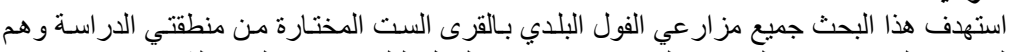
شاملة البحث وعينته

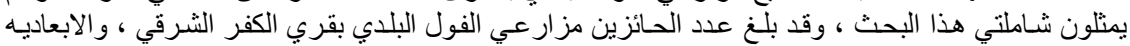

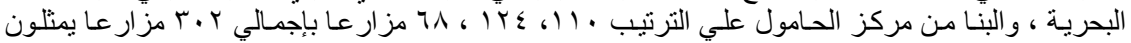

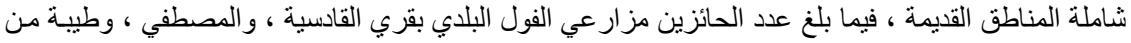

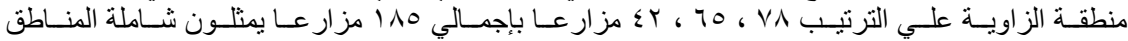

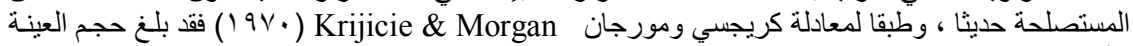

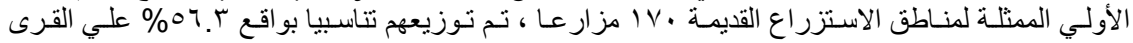

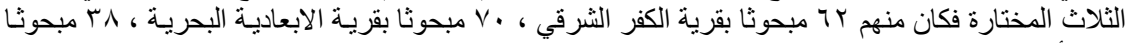

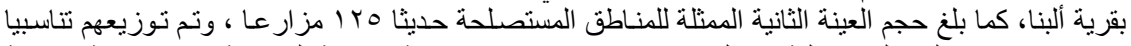

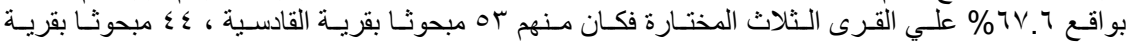

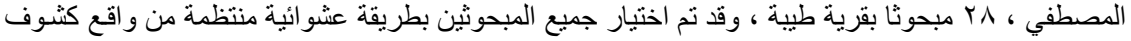

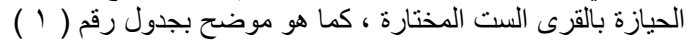

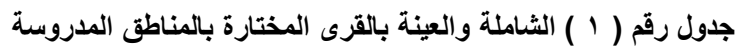

\begin{tabular}{|c|c|c|c|c|c|c|c|c|}
\hline \multirow{2}{*}{ والثمانمة } & \multicolumn{3}{|c|}{ قري مناطق الاستزراع المستصلحة حليثا } & \multirow{2}{*}{ والجماليّي } & \multicolumn{3}{|c|}{ قرّي مناطق الاستزراع القليمة } & \multirow[t]{2}{*}{ القرى } \\
\hline & طيبة & المصطفي & 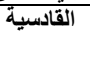 & & ألبنا & الابعرادية & الشرقفي & \\
\hline 110 & $\varepsilon r$ & 70 & $\mathrm{VA}$ & $r \cdot r$ & 71 & Ir乏 & 11. & 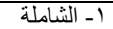 \\
\hline iro & rA & $\varepsilon \varepsilon$ & or & iv. & rی & $v$. & r & r- العينة \\
\hline
\end{tabular}

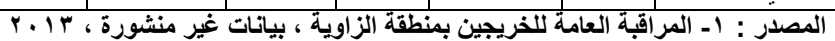

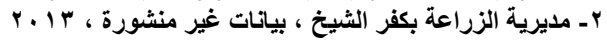

أسلوب جمع وتحليل البيانات 
استخدم الاستبيان بالمقابلـة الشخصية كأداة لجمسع بيانـات الدر اسـة وذلك بعد اختبـار صـلاحية استمارة

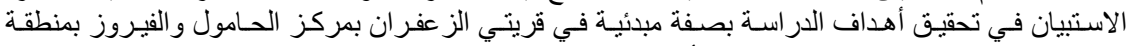

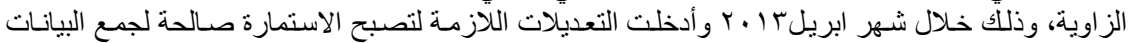

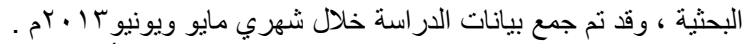

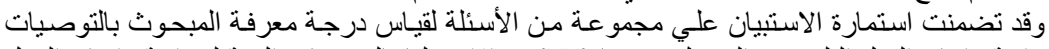

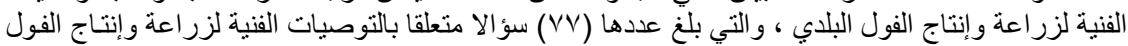

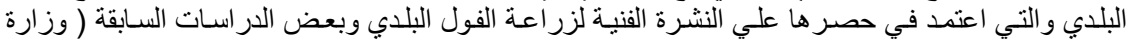

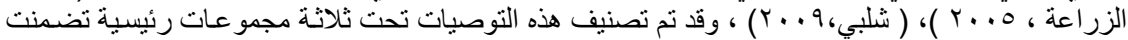

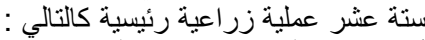

أولا:مجموعة التوصيات الفنية لعمليات ما قبل زراعة فئة محصول الفول البلدي واشتملت علي 9 اتوصية كمـا

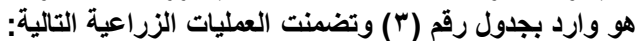

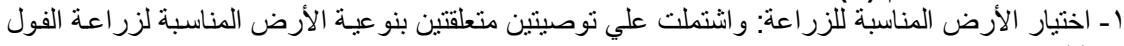
البلدي.

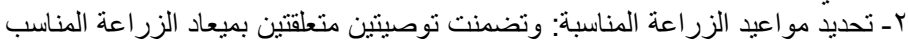

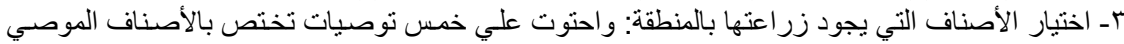

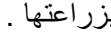

ع - خدمة وتجهيز الأرض قبل لزراعة: وتضمنت توصيتين متعلقتين بالعمليات الزر اعية اللازم القيام بها.

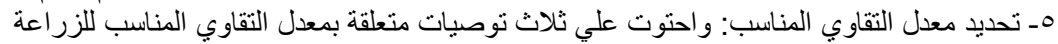

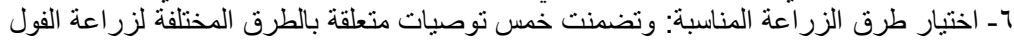

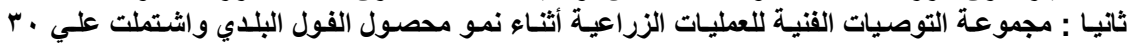

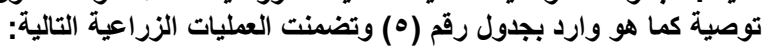

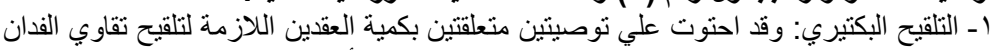

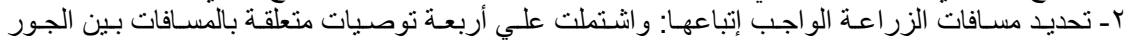

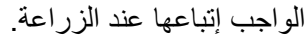

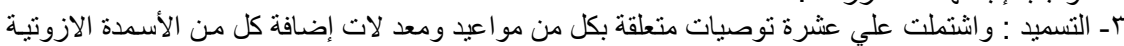

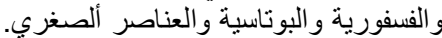

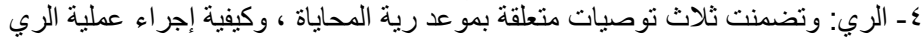

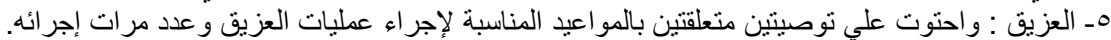

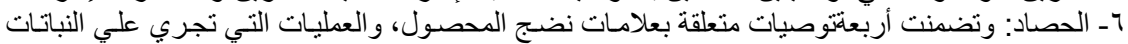

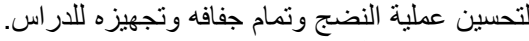

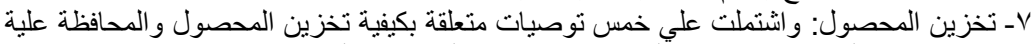

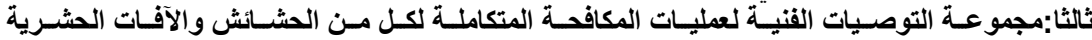

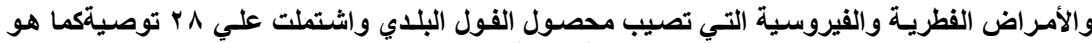

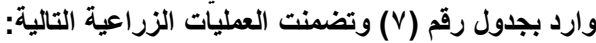

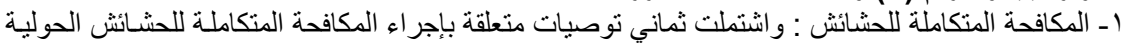

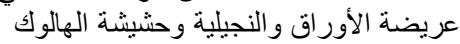

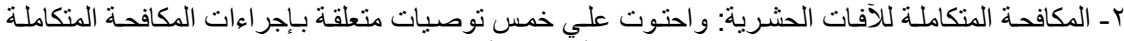

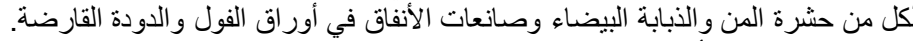

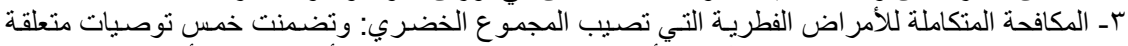

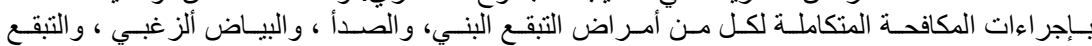

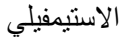

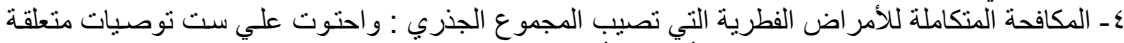

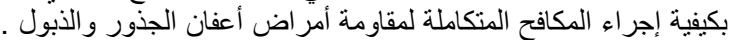

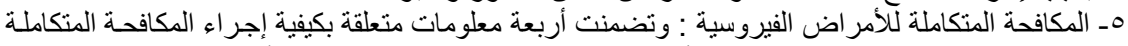
لفيروسات تبرقش الفول البلدي والتفاف أوراق البسلة وذبول الفيكة الفول و الموازيك الأصفر و الموازيك الحقيقي وتبقع الفول البلدي 


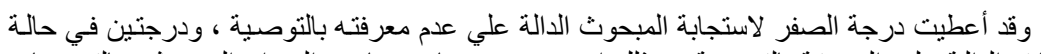

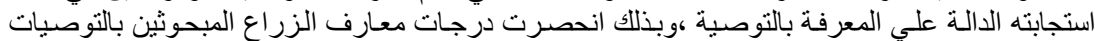

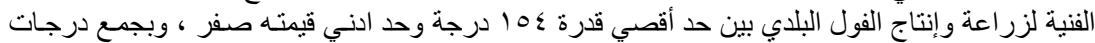

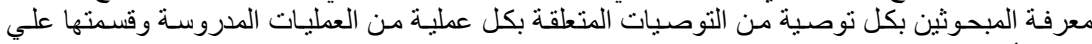

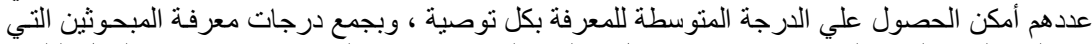

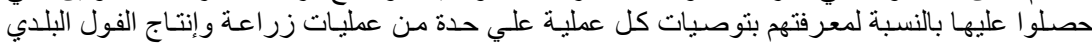

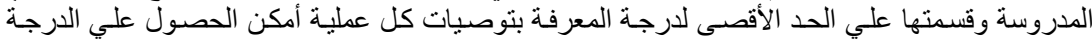

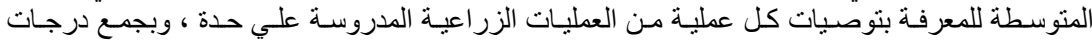

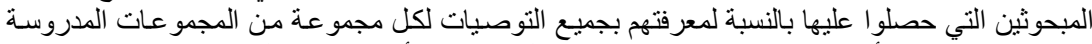

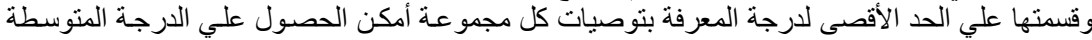

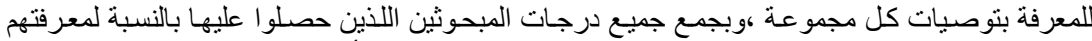

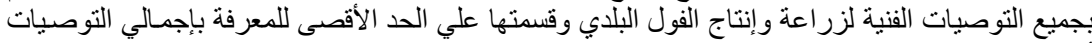

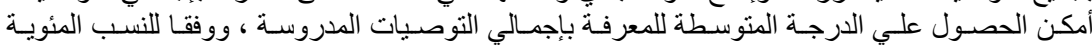

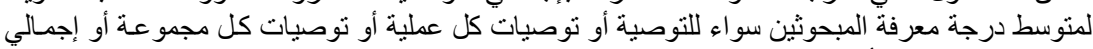

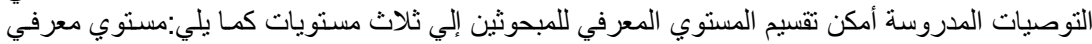

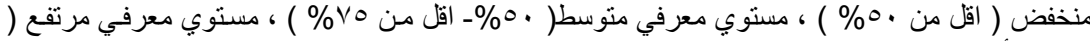

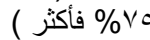

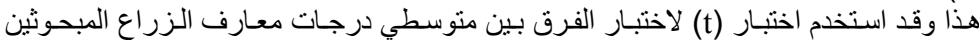

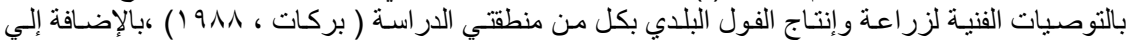
المتوسط الحسابي، والانحر اف المعياري، والتباين ، و والعرض ألجدولي بالتكرار اتل وات والنسب المئوية.

\section{النتائج ومناقثتها}

أولا : مستوي معارف الزراع المبحوثين بالتوصيات الفنية لزراعة وإنتاج الفول البلاي بكل من المنطقة

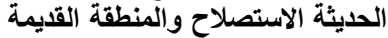

اـ مستوي معارف الزراع المبحوثين بالتتوصيات الفنبة المتعلقة بالعمليات الزراعية قبل زراعة محصول

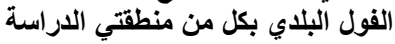

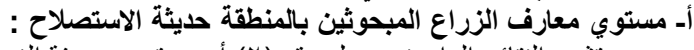

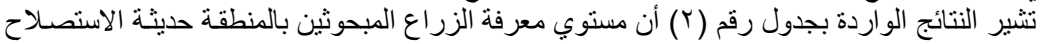

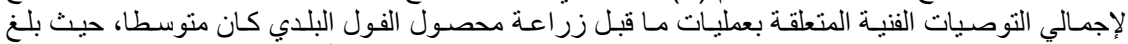

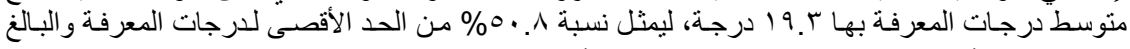

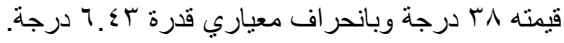


جدول رقم (r): المتوسطات والانحرافات المعيارية لدرجات معارف الزراع المبحوثين بالتوصيات المتعلقة

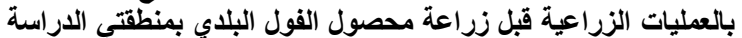

\begin{tabular}{|c|c|c|c|c|c|c|c|c|c|c|}
\hline \multicolumn{4}{|c|}{ الزراع المبحوثينين بالمناطق } & \multicolumn{4}{|c|}{ الزراع المبحوثين بالمناطق } & \multirow{2}{*}{ الارجاتى المعرفة } & \multirow[t]{2}{*}{ البيان } & \multirow[t]{2}{*}{ ? } \\
\hline مستوفي & \% الارجة من & الالمعرافي & الأوجات & المعرفة & الألية من & المعياري & الديط & & & \\
\hline مرتفع & VV.r & $\cdot . \mathrm{rV}$ & $r .9$ & متوسط & $0 . r^{r}$ & $\cdot .94$ & r. .1 & $\varepsilon$ & اخلزراعة اخـار الأرض المناســـــبة & 1 \\
\hline 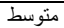 & TV.A & $. . \mathrm{V} \leqslant$ & r.Y & 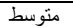 & $7 \cdot . \cdot$ &.$A T$ & T..$\theta_{0}$ & $\varepsilon$ & تحديد مو اعيد الزراعة المناسبة & r \\
\hline متوسط & or. 1 & T.1T & 0.4 & منخفض | | | | من & $\varepsilon r . \wedge$ & T.T. & $\varepsilon .4 \wedge$ & 1. & 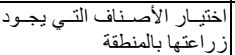 & $r$ \\
\hline مرتفع & 90. & $\cdot r^{\prime}$ & r.A. & مرتفع & Ar.^ & .01 & r.r. & $\varepsilon$ & الزر اعدة وتجهيـز الأرض قبــل & $\varepsilon$ \\
\hline 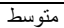 & $77 . \mathrm{Y}$ &. .10 & $\xi \ldots$ & منخفض & $r \Lambda . r$ & T.T1 & t.r. & 7 & |تحديد معدل التقاوب المناسب & 0 \\
\hline مرتفع & 94.4 & 1.17 & $7 . r 4$ & منخفض & $\leqslant 9$. & T.A६ & $\leqslant .9$. & $1 \cdot$ & اختيار طرق الزراعة المناسبة & 7 \\
\hline متوسط & 74.1 & 0.17 & ro.r & متوسط & 0.11 & $7 . \leqslant T$ & 19.5 & rᄉ & بالي & الإج \\
\hline
\end{tabular}

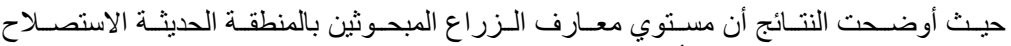

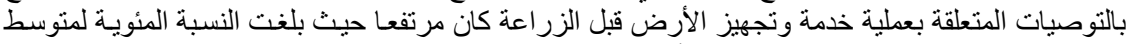

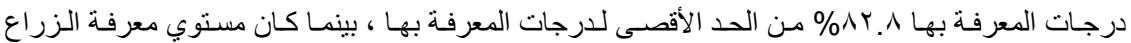

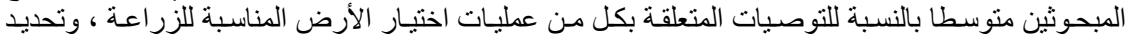

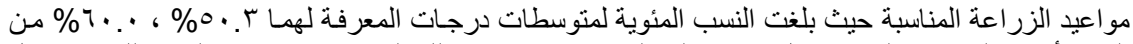

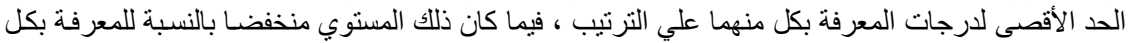

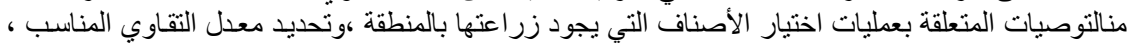

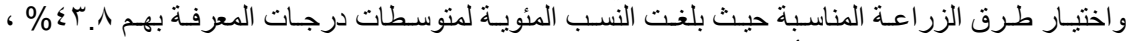

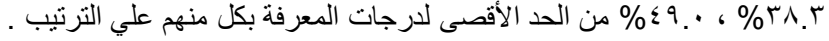

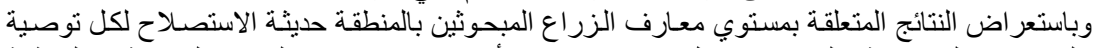

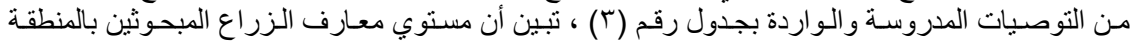

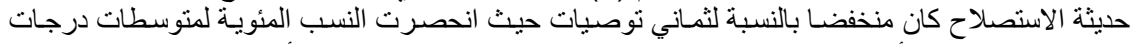

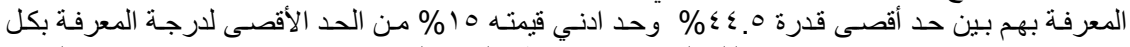

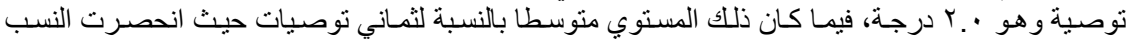

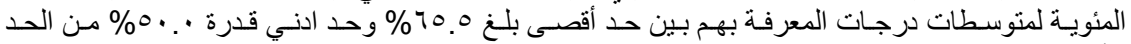

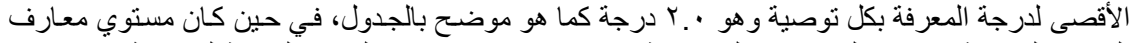

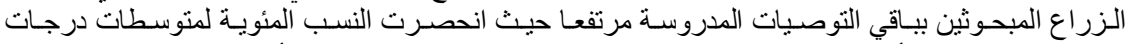

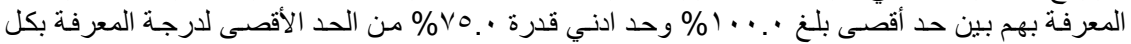

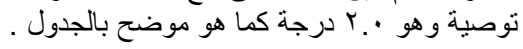


Zedan, E. A. A

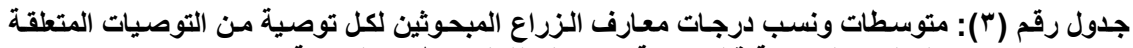

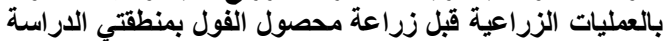

\begin{tabular}{|c|c|c|c|c|c|c|c|}
\hline \multicolumn{3}{|c|}{ الزراع المبحوثين بالمناطق } & \multicolumn{3}{|c|}{ الزراع المبحوثُين بالمناطق حذيثا } & \multirow[t]{2}{*}{ البيان } & \\
\hline للتوصية & $\%$ & اللمعرفة اللمبة & للتوصية & $\%$ & 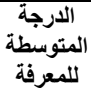 & & \\
\hline منوسط & $9 \cdot$. & $\begin{array}{l}1.1 . \\
1.49\end{array}$ & منخفض من من من & $\begin{array}{l}01.0 \\
\leqslant \leqslant .0\end{array}$ & $\begin{array}{l}1.11 \\
.199\end{array}$ & 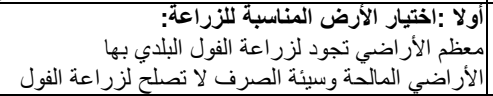 & $\begin{array}{l}-4 \\
-1\end{array}$ \\
\hline من منف & $\begin{array}{l}9 ., 0 \\
\leqslant 0,0\end{array}$ & $\begin{array}{l}1 . \wedge \\
\therefore .91 \\
\end{array}$ & منخفض & $\begin{array}{l}A \cdot . \cdot \\
\varepsilon \cdot . \cdot\end{array}$ & $\begin{array}{l}1.7 \\
\therefore . \\
\end{array}$ & 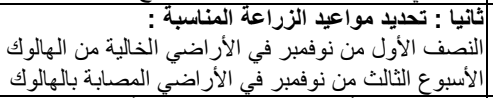 & ז \\
\hline من منخفط منف منف & $\begin{array}{l}\mathrm{v}, 0 \\
\gamma \cdot . \\
\varepsilon \cdot . \\
\varepsilon \cdot . \\
\varepsilon \cdot .\end{array}$ & $\begin{array}{l}1.01 \\
1 . \varepsilon . \\
. \wedge \\
. \wedge . \\
. \wedge .\end{array}$ & من منوسط منفط & $\begin{array}{l}r \leqslant .0 \\
r \leqslant .0 \\
0 . . \\
r . . \\
r . .\end{array}$ & $\begin{array}{l}1 . r q \\
1 . r q \\
1 . \cdots \\
\ddots \varepsilon . \\
\ddots \varepsilon .\end{array}$ & |ثالثا : اختيار الأصناف التي تجود بالمنطقة & $\begin{array}{l}-1 \\
-r \\
-r \\
-\varepsilon \\
-0\end{array}$ \\
\hline 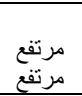 & $\begin{array}{l}1 \cdots \cdot \\
9 \cdot .\end{array}$ & $\begin{array}{l}r . \cdots \\
i . \wedge .\end{array}$ & متوسطع & $\begin{array}{l}1 \% .0 \\
10.0\end{array}$ & $\begin{array}{l}r . \cdots \\
i . \mu\end{array}$ & 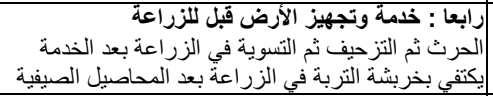 & $\begin{array}{l}-4 \\
-1\end{array}$ \\
\hline منوسط من منط & $\begin{array}{l}\text { Vo.0 } \\
T \leq .0 \\
T . .0\end{array}$ & $\begin{array}{l}1.01 \\
1.49 \\
1.49\end{array}$ & منخفض منض منض & $\begin{array}{l}00 . \\
\varepsilon \cdot . \\
r \cdot .\end{array}$ & $\begin{array}{l}1.1 \\
\ddots 1 \\
. \varepsilon\end{array}$ & 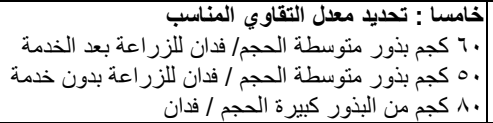 & $\begin{array}{l}-1 \\
-r \\
-r\end{array}$ \\
\hline من مرتفع مرتفع مرتفع & $\begin{array}{l}9 . .0 \\
v 0.0 \\
00.0 \\
\text { vo.0 } \\
r . . .\end{array}$ & $\begin{array}{l}1.1 . \\
1.01 \\
1.11 \\
1.01 \\
. .2 .\end{array}$ & من منف منفط منف منف & $\begin{array}{l}0 . . \\
\text { vo." } \\
r . . \\
00 . \\
10 .\end{array}$ & $\begin{array}{l}1.7 . \\
1.0 . \\
. .5 . \\
1.1 . \\
.7 .\end{array}$ & 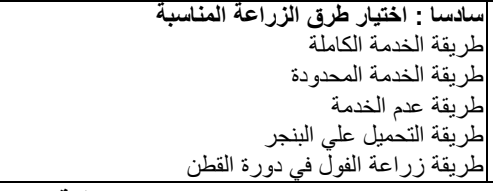 & $\begin{array}{l}-1 \\
-r \\
-4 \\
-\varepsilon \\
-0\end{array}$ \\
\hline
\end{tabular}

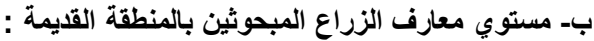

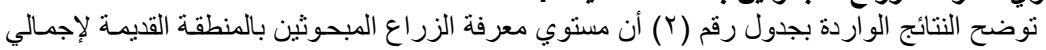

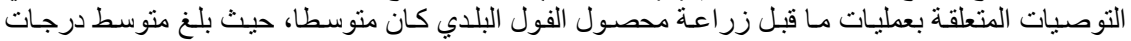

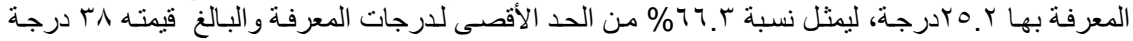

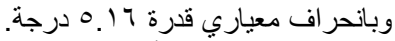

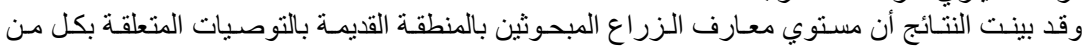

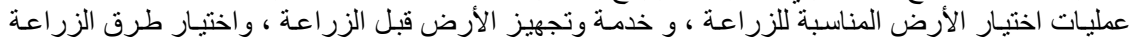

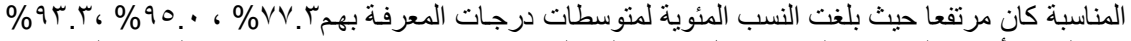

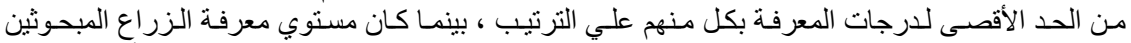

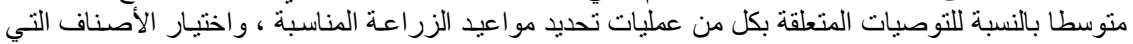

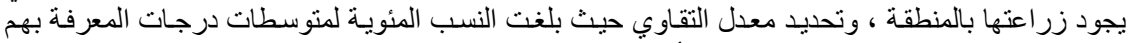

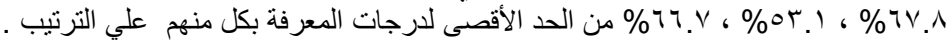

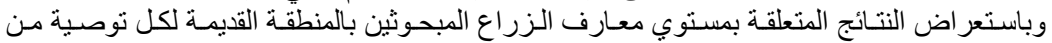

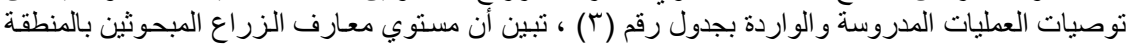

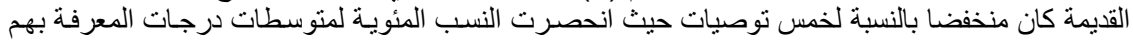

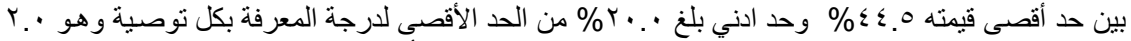

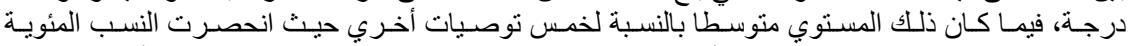

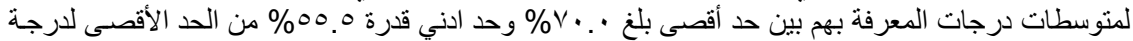

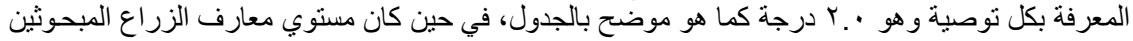

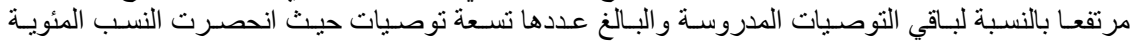




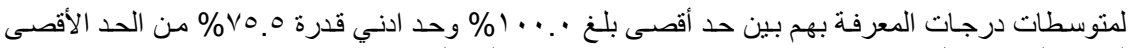

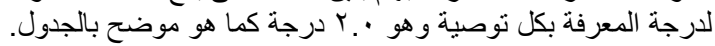

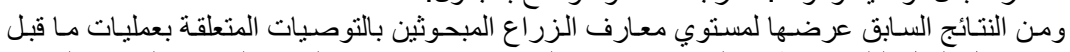

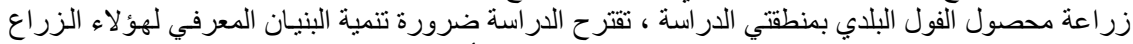

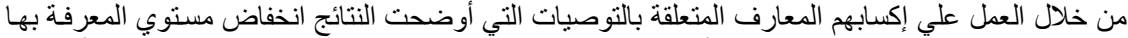

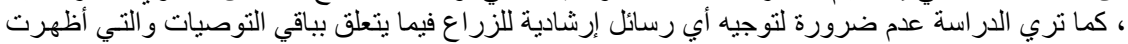

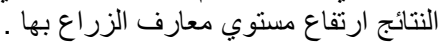

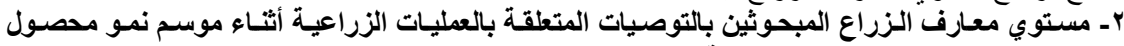

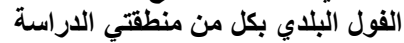

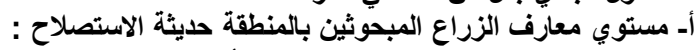

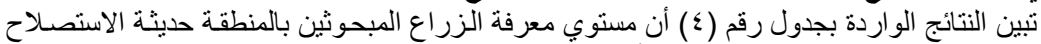

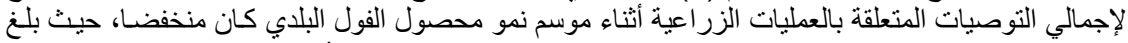

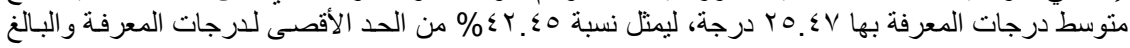

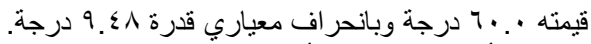

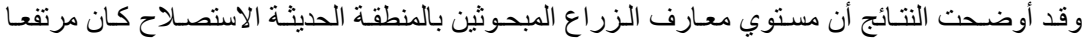

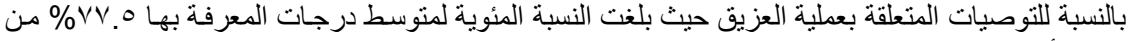

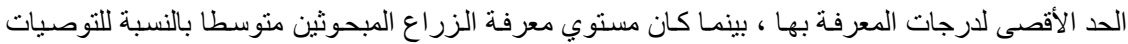

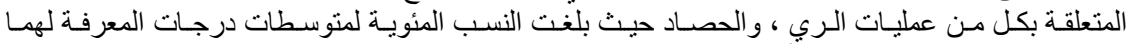

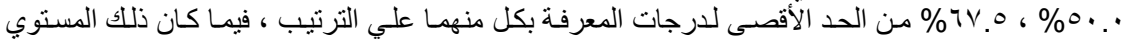

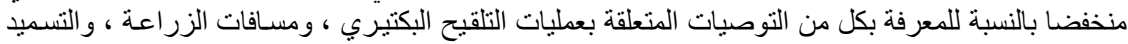

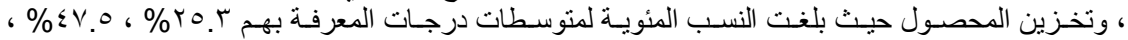

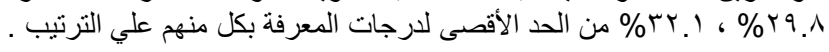

جدول رقم (؛ ): المتوسطات والانحرافـات المعياريـة للدرجات معارف الزراع المبحوثين للتوصيات المتعلقة

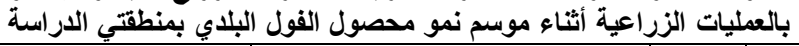

\begin{tabular}{|c|c|c|c|c|c|c|c|c|c|c|}
\hline \multicolumn{4}{|c|}{ الزراع المبحوثينين بالمناطق } & \multicolumn{4}{|c|}{ 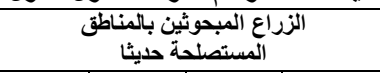 } & \multirow{3}{*}{ الألماتى } & \multirow[t]{3}{*}{ البيان } & \\
\hline مستوي & \% من \% & |الانحراف & متوسط & مستوي & \% من & الانحراف & متوسط & & & \\
\hline المعرفة & الكلية الإجة & المعياري & الارجات & المعرفة & الكلية الاجة & المعياري & الارجات & & & \\
\hline منخفض & 10. & I.Ar &. .7 & منخفض & ro.r & $1 . r v$ & 1.9 & $\varepsilon$ & التلقيح البكتيري & 1 \\
\hline متوسط & TY.A & T.V. & 0.0 & منخفض & $\varepsilon Y_{.0}$ & T.1 & r.A. & 1 & مسافات الزر اعة & r \\
\hline منخفض & rT. & $\varepsilon .97$ & 7.71 & منخفض & r9.1 & $7 . \varepsilon$ & 0.90 & $r$. & التسميد & $\Gamma$ \\
\hline منوسط & $4 . V$ & $1 . r 1$ & T.AT & متوسط & $0 .$. & $1 . \cdot 1$ & $r . .$. & 7 & الري & $\varepsilon$ \\
\hline مرتفع & $9 \cdot . \cdot$ & $\because \cdot \wedge$ & T.T. & مرتفع & VV.O & $\cdot .7 \varepsilon$ & ז.1. & $\varepsilon$ & |العزيق & 0 \\
\hline مرتفع & $1 \Lambda .9$ &. .17 & V.11 & متوسط & $7 \% .0$ & I.VY & $0 . \xi$. & $\Lambda$ & الحصاد & 7 \\
\hline متوسط & $7 \pi .1$ & T.91 & 7.41 & منخفض & Tr. & T. ¿A & $r . r u$ & 1. & تخزين المحصول & v \\
\hline منوسط & 00.1 & $\frac{V .0}{0}$ & Tr.I乏 & منخفض & $\varepsilon r . \leqslant 0$ & $9 . \leqslant \wedge$ & YO. हV & 7. & & 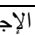 \\
\hline
\end{tabular}

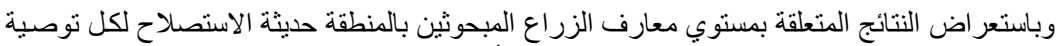

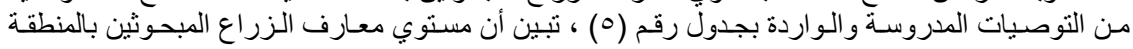

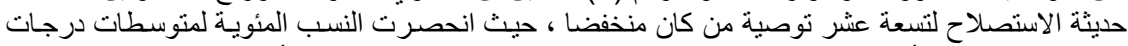

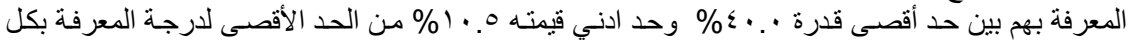

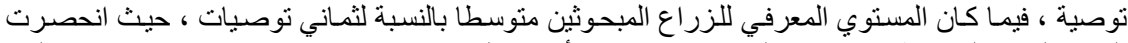

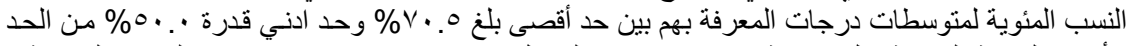

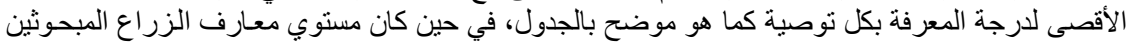

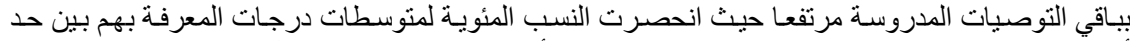

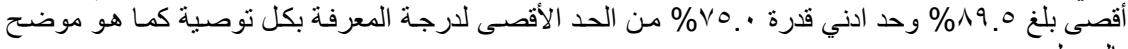


ب- مستوي معارف الزراع المبحوثين بالمنطقة القديمة :

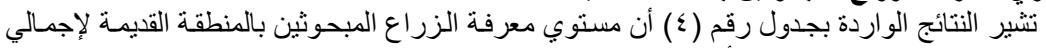

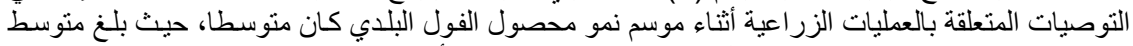

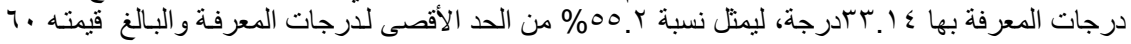

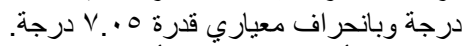

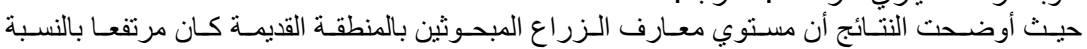

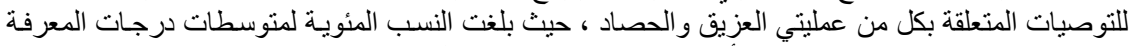

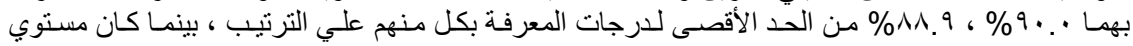

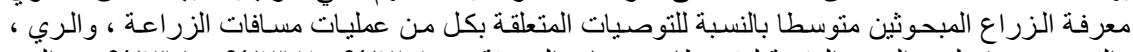

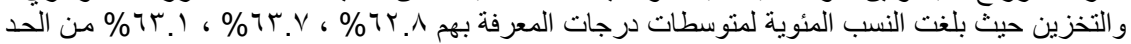

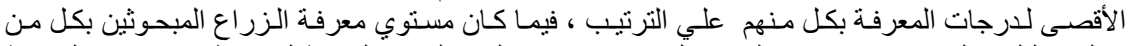

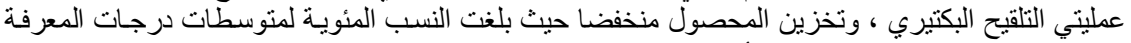

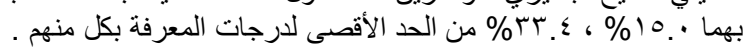

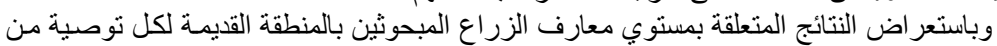

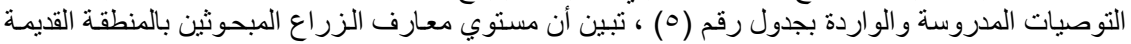

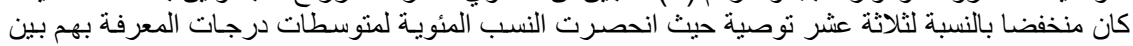

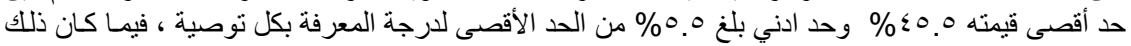

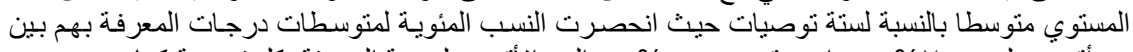

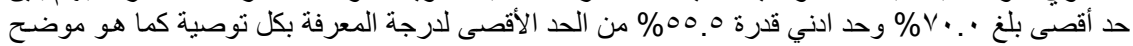

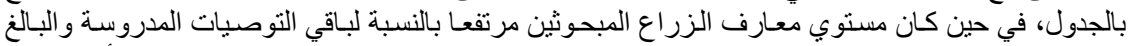

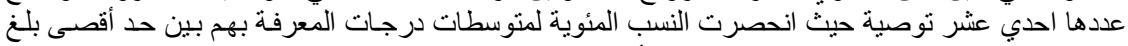

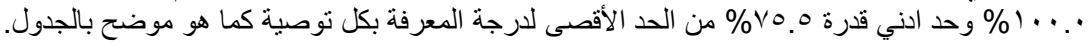

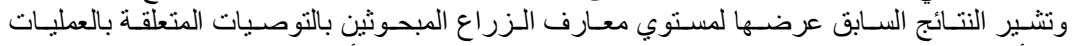

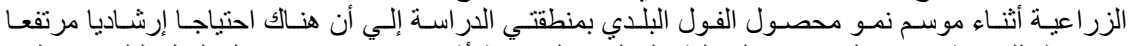

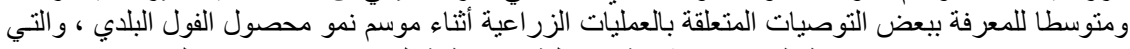

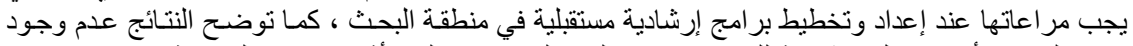

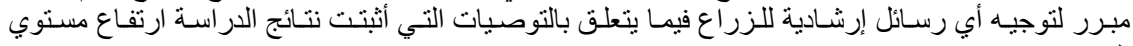
الزراع بها ـ الئ 


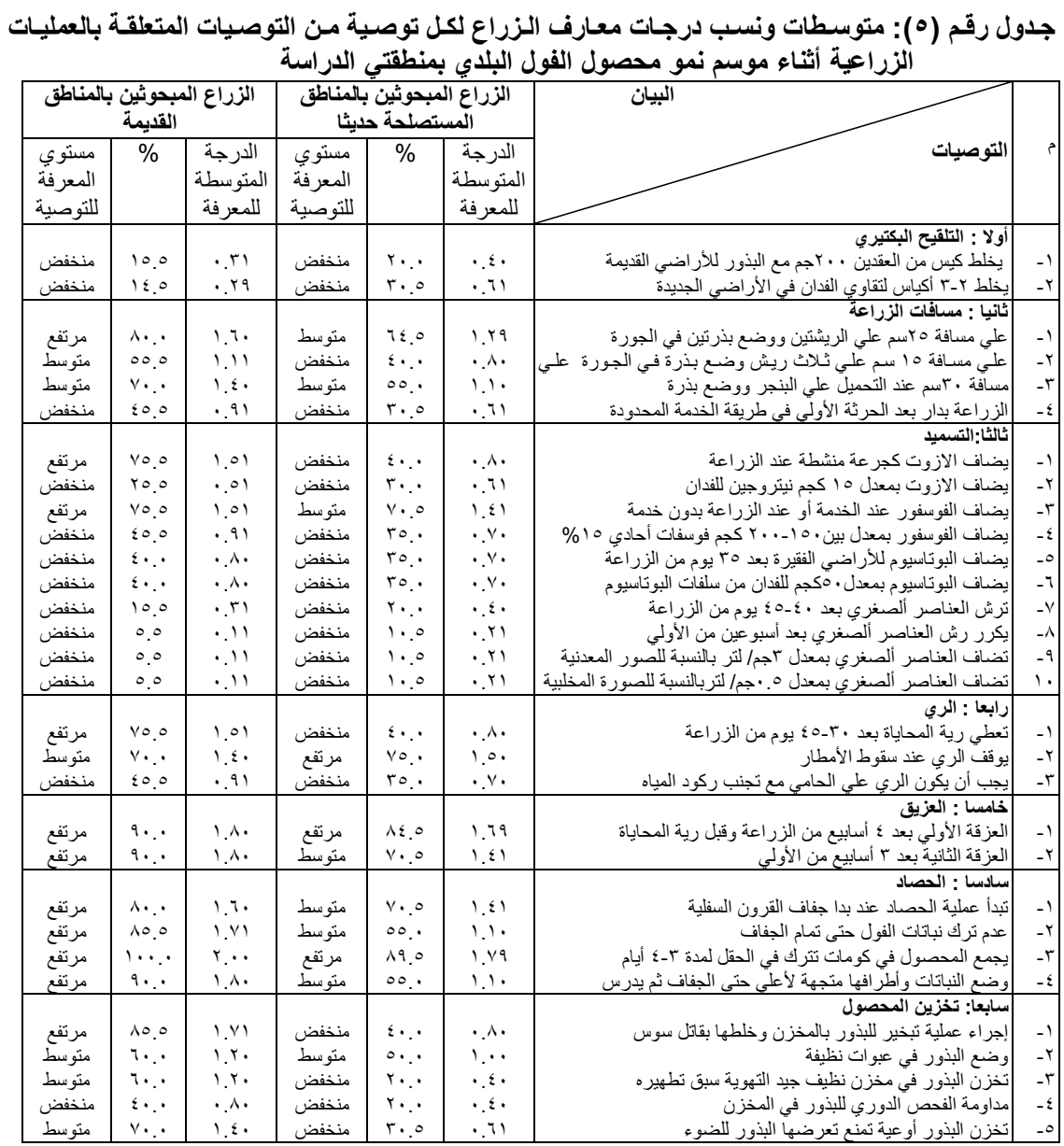

بـ مستوي معارف الزراع المبحوثين بالتوصيات المتعلقة بعمليات المكافحة المتكاملة لكل من الطشائش والآفات الحشرية والأمراض الفطرية والفيروسية التي تصيب محصول الفول البعلئ البلاي بكل من منطقتي

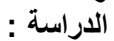

أ- مستوري معارف الزراع المبحوثين بالمنطقة حديثة الاستصلاح :

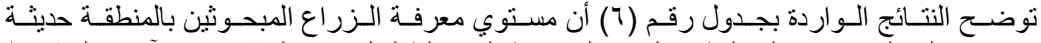

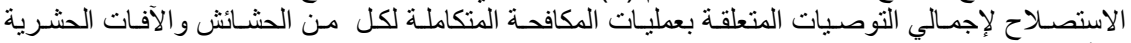

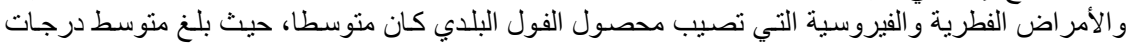

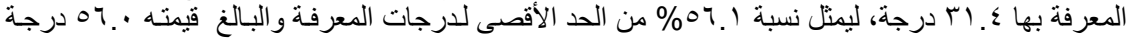

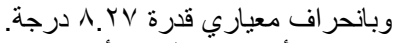

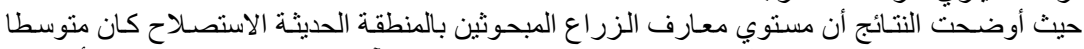

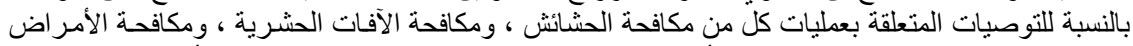

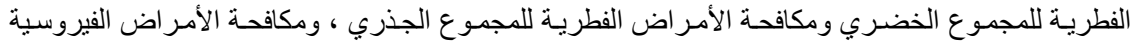

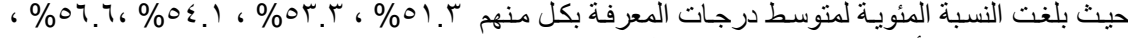

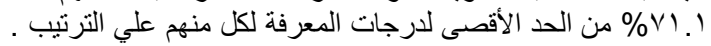


جدول رقم (7) المتوسطات والاتحرافات المعيارية لارجات معارف الزراع المبحوثين بالتوصيات المتعلقة

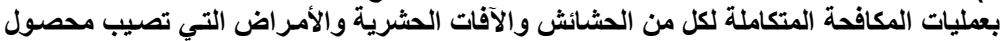

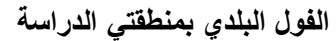

\begin{tabular}{|c|c|c|c|c|c|c|c|c|c|c|}
\hline \multicolumn{4}{|c|}{ الزراع المبحوثيُّن بالمناطق } & \multicolumn{4}{|c|}{ الزراع المبحوثُّين بالمناطق } & \multirow{3}{*}{ لالأقصى الحات } & \multirow[t]{2}{*}{ البيان } & \\
\hline مستوي & 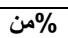 & الانحراف & متوسط & مستوي & \% من \% & الانحراف & متوسط & & & \\
\hline المعرفة & الكلية & المعياري & الارجات & المعرفة & الكلية & المعياري & الارجات & & 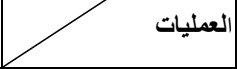 & \\
\hline 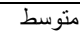 & $7 \varepsilon . \varepsilon$ & T. $\cdot \varepsilon$ & $1 \cdot . r \cdot$ & متوسط & 01.5 & T.Y. & A.Y. & 17 & مكافحة الحشائش & 1 \\
\hline متوسط & 01. & 1.17 & $0 . \lambda Y$ & متوسط & 0.1 & 5.9 & 0.4 & 1. & مكافحة الآفات الحشرية & $\bar{r}$ \\
\hline متوسط & 79.1 & T.IY & 7.91 & متوسط & $0 \leqslant .1$ & 1.04 & $0 . \leqslant 1$ & 1. & للمجموعة الإمضر اضري الفظريـة & $\Gamma$ \\
\hline متوسط & $V \varepsilon . \varepsilon$ &. .71 & 1.94 & | متوسط & 0.7 & $T . \cdot V$ & 7.19 & $\pi$ & 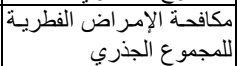 & $\varepsilon$ \\
\hline 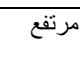 & $\lambda \Lambda_{\text {. }} \Lambda$ & $\cdot . \mu \Lambda$ & 7.74 & | متوسط & VI. & 1.9 & 0.79 & $\Lambda$ & 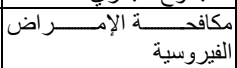 & 0 \\
\hline متوسط & 71.9 & $7 . \leqslant 1$ & $r \Lambda .0 \wedge$ & | متوسط & 07.1 & A.rV & r. & 07 & & \\
\hline
\end{tabular}

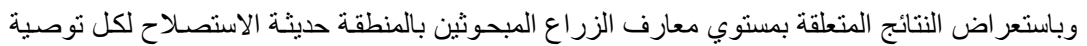

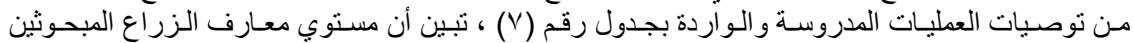

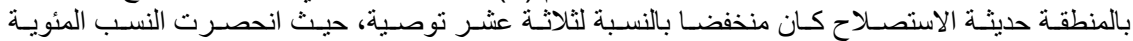

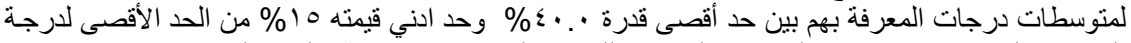

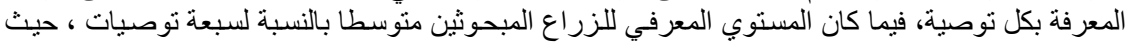

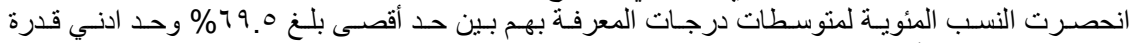

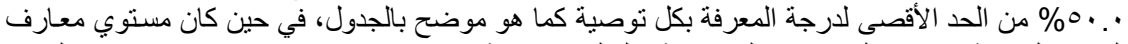

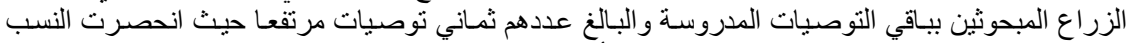

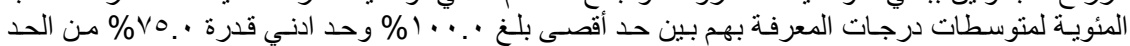

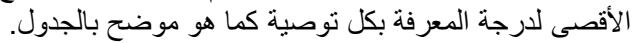

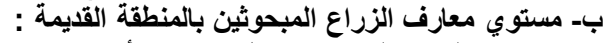

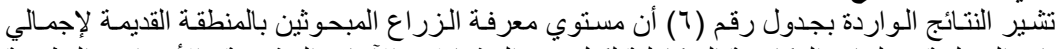

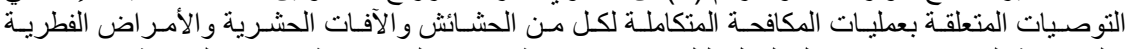

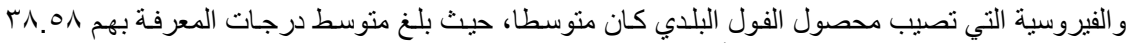

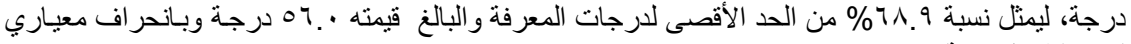

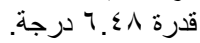

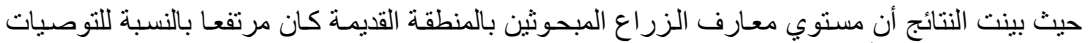

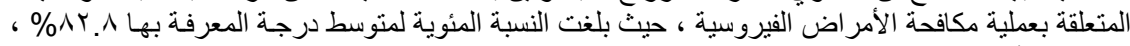

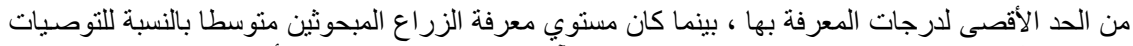

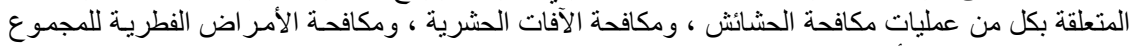

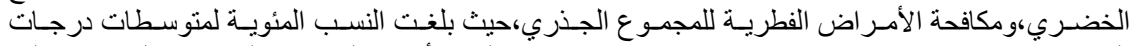

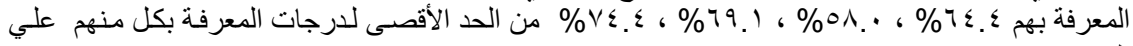


جدول رقم (V): متوسطات ونسب درجات معارف الزراع المبحوثين لكل توصبة من التوصيات المتعلقة

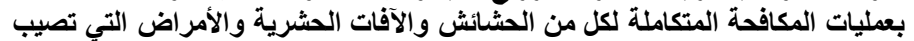

محصول الفول البلاي بمنطقتي الاربلة البنة

\begin{tabular}{|c|c|c|c|c|c|c|c|}
\hline \multicolumn{3}{|c|}{ 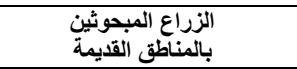 } & \multicolumn{3}{|c|}{ الزراع المبحوثين بالمناطق حيثا } & \multirow[t]{2}{*}{ البيان } & \multirow[b]{2}{*}{ त } \\
\hline للتوصية المعرفة & $\%$ & اللمتوسطة المبة & للتوصية & $\%$ & اللمتوسة المة & & \\
\hline & & & & & & |أولا لمكافحة الحشائش العشائش العادية & \\
\hline 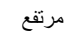 & $1 \cdots \cdot$ & $r_{.} \cdot$ & 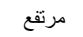 & $1 \cdots \cdot$ & r... & 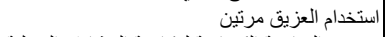 & -1 \\
\hline مرتفع & $\wedge \cdot . \cdot$ & 1.7 & 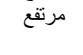 & vo. & 1.0 & تبـ لمكافحة حشيشة المقاومة الهائوكة لمكافحة الحشائش النجيلية & $-r$ \\
\hline 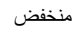 & $\leqslant 0.0$ & .91 & منخفض & 10. & e.r. & تأخير ميعاد الزر أعة من V-. أيام & -4 \\
\hline 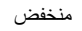 & $\varepsilon \cdot$ & $\cdot \wedge$. & 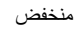 & $r \cdot . \cdot$ & $\cdot \varepsilon$ & الزر اعة بدون خدمة & $-\varepsilon$ \\
\hline 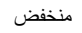 & $\varepsilon \cdot$. & $\cdot \wedge$. & 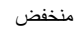 & $r \cdot$. & $\cdot \varepsilon$ & | عدم تعطيش المحصول & -0 \\
\hline 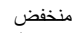 & $\varepsilon \cdot$. & $\cdot \wedge$. & 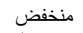 & $r \cdot$. & $\cdot \varepsilon$ & الالتز ام بزر اعة الكثافة الموصي بها & -7 \\
\hline متوسط & $v \cdot . \cdot$ & $1 . \varepsilon$ & متوسط & $7 .$. & i.r. & إز الة الشماريخ بمجرد ظهور هاً في الإصابة الخفيفة & $-v$ \\
\hline مرتفع م مرت & $1 \cdots$ & r... & مرتفع & $1 \ldots$ & r... & استخدام المقاومة الكيماوية في حالة الإصابة الثديدة & $-\lambda$ \\
\hline & & & & & & ثثانيا : مكافحة الآفات الحشريةّة & \\
\hline متوسط & $7 .$. & I.r. & منوسط & $7 .$. & $1 . r$. & | مقاومة الحشائش الموجودة الحقل & -1 \\
\hline منخفض & $\leq 0.0$ & .91 & 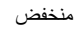 & 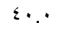 & $\cdot A$. & | افتلاع النباتات المصابة & $-r$ \\
\hline 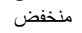 & $\leqslant 0.0$ & .91 & 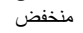 & $\varepsilon \cdot \cdot$ & $\therefore$. & تنظيم عمليات الري ت & $-r$ \\
\hline 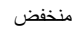 & $\varepsilon \cdot$. & $\therefore \wedge$. & 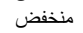 & ro. 0 & .01 & عدم الإسراف في أستخدام الأسمدة الازوتية & $-\varepsilon$ \\
\hline مرتفع & $1 \cdots \cdot$ & r... & مرتفع & $1 \cdots \cdot$ & r... & رش الحواف و البّؤر المصابة بالمبيدات الموصي بها & -0 \\
\hline 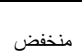 & $\varepsilon \cdot$. &.$\wedge$. & 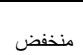 & $r . .0$ & .71 & 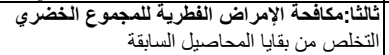 & -1 \\
\hline 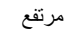 & $\wedge \cdot$. & 1.7 & منخفض & $\varepsilon \cdot \cdot$ & $\because \wedge$. & الاهتمام بعمليات الحرث للتربة & $-r$ \\
\hline مرتفع & 10.0 & 1.21 & منوسط & 79.0 & $1 . r 9$ & زراعة الأصناف المقاومة & $-r$ \\
\hline 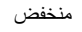 & $\varepsilon \cdot \cdot$ & $\cdot \wedge$. & 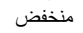 & $r \cdot .0$ & .71 & |زراعة تقاوي معتمدة & $-\varepsilon$ \\
\hline 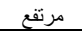 & $1 \cdots \cdot$ & r... & 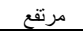 & $1 \cdots \cdot$ & $r .$. & | المقاومة الكيماوية برش المبيدات الموصي بها & -0 \\
\hline مرتفع & 10.0 & 1.21 & متوسط & 79.0 & $1 . r 9$ & 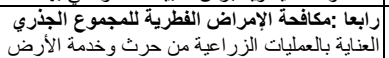 & -1 \\
\hline متوسط & 00.0 & 111 & منخفض & $\varepsilon \cdot$ & $\therefore$. & 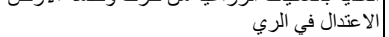 & -4 \\
\hline 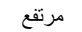 & A. . & 1.7. & متوسط & $0 .$. & $1 . \cdots$ & | التخلص من النباتات المصابة وحرقها & $-r$ \\
\hline مرتفع & A.. & 1.7. & منوسط & $v \cdot .0$ & $1 . \S 1$ & 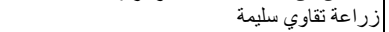 & $-\varepsilon$ \\
\hline متوسط & 00.0 & 1.11 & 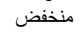 & $r \cdot . \cdot$ & $\cdot$. & الززراعة علي عمق مناسب & -0 \\
\hline 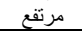 & $9 \cdot$. & I.A. & مرتفع & 19.0 & 1.199 & |معاملة البذورّ قبل الزراعة بمطهر فطري & -7 \\
\hline & & & & & & خامسا : مكافحة الإمراض الفيروسية & \\
\hline 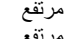 & $\ddot{1} \ddot{0}$ & i.. & مت مرتفع & 19.0 & 1.19 & |زاعرة الأصناف الموصي بها & $\begin{aligned}-1 \\
-4\end{aligned}$ \\
\hline منخفض مرت & $\leqslant 0.0$ & $\begin{array}{l}.81 \\
.91\end{array}$ & 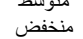 & $\begin{array}{ll}12.0 \\
4 . .0\end{array}$ & $\begin{array}{l}1.89 \\
.71\end{array}$ & |مقاومة الحشير الموات الناقلة للأمر اضي بها الفيروسية & $\begin{array}{l}-r \\
-r\end{array}$ \\
\hline مرتفع & $1 \cdots$ & $r .$. & مرتفع & $1 \cdots$ & $r .$. & |تقليع النباتات المصابة وحرقها & $-\varepsilon$ \\
\hline
\end{tabular}

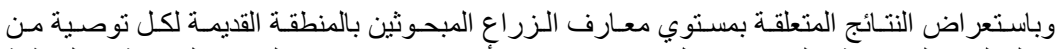

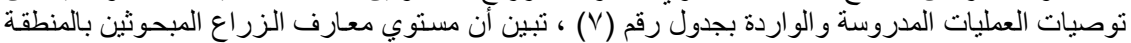

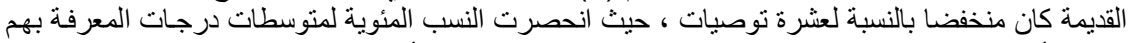

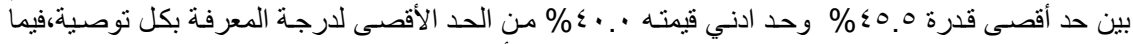

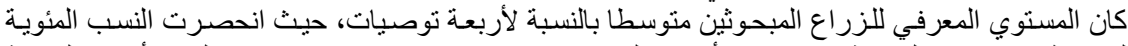

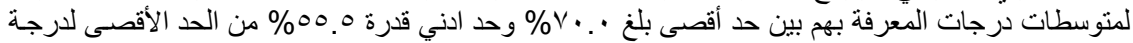

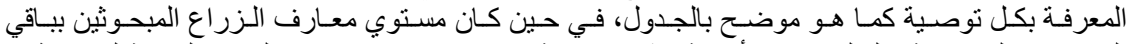

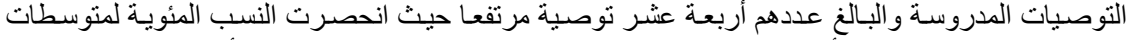

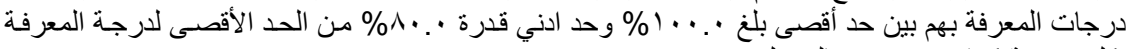

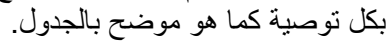

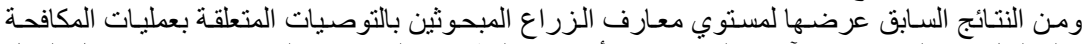

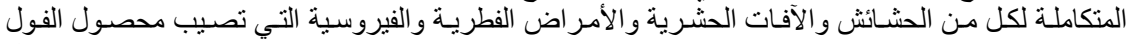

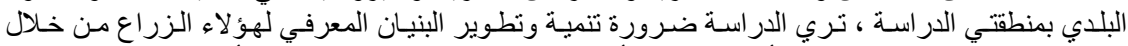

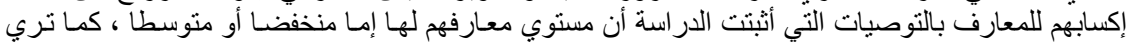


Zedan, E. A. A

الدر اسـة عدم وجود ضـرورة لتوجيهه أي رسـائل إرشـادية للزر اع فيمـا يتصل بالتوصيات التي أثبتت الدراسـة

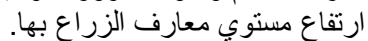

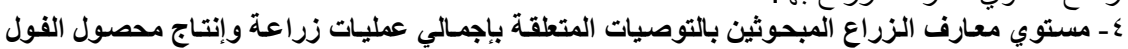

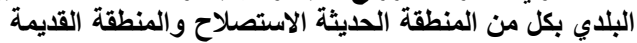

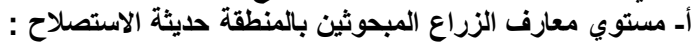

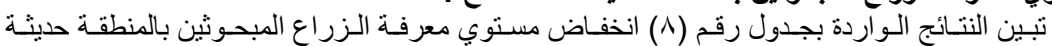

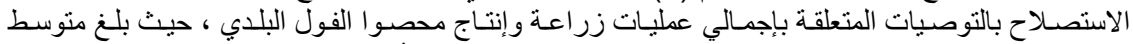

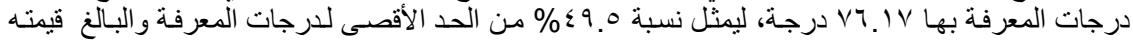

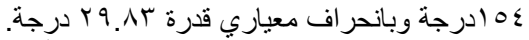

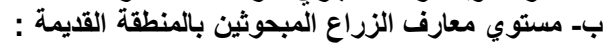

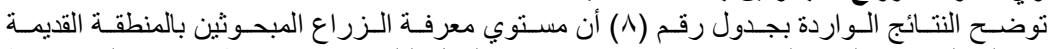

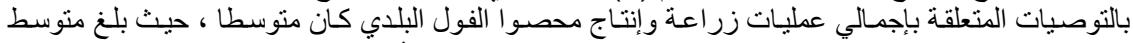

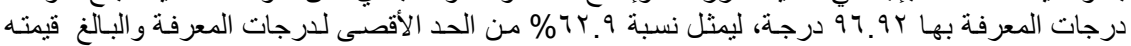

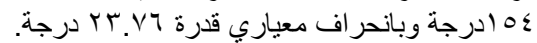

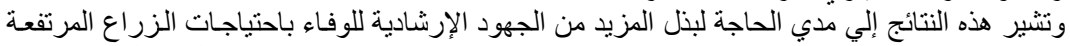

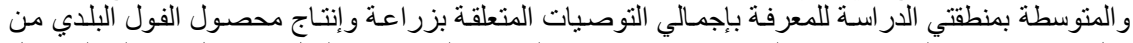

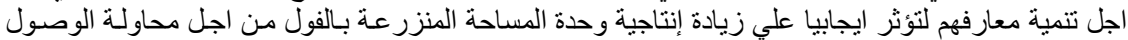

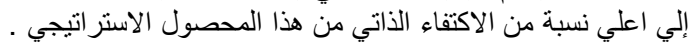

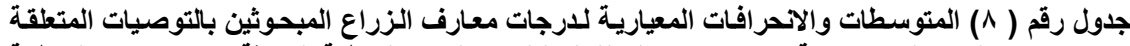

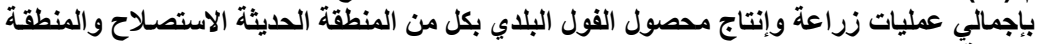

\begin{tabular}{|c|c|c|c|c|c|c|c|c|c|c|}
\hline & & & & & & & & & \multicolumn{2}{|l|}{ القديمه } \\
\hline \multicolumn{4}{|c|}{ الزراع المبحوثيني بالمناطق } & \multicolumn{4}{|c|}{ 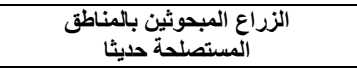 } & |الأصىى & & \\
\hline المعتوفة & $\%$ & |الانحرياري & الدرجات & |المعرفةتي & $\%$ & المعياري & الدتوسات & اللارجاتة & & \\
\hline متوسط & 74.9 & rT.VI & 97.94 & منخفض & $\leqslant 9.0$ & $r q . \wedge r$ & $\mathrm{~V} . \mathrm{IV}$ & $10 \leqslant$ & 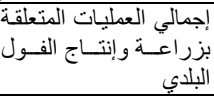 & -1 \\
\hline
\end{tabular}

ثانيا : الفروق بين معارف الزراع المبحوثين

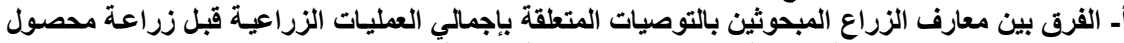

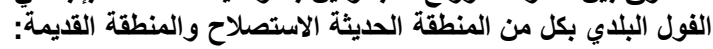

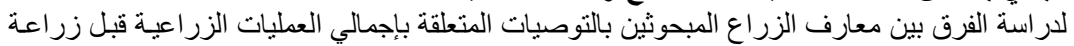

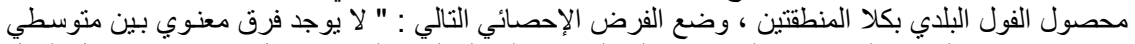

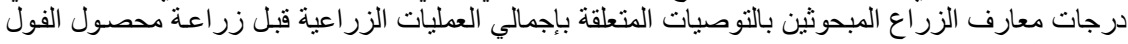

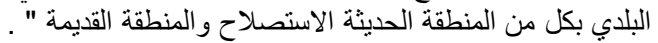

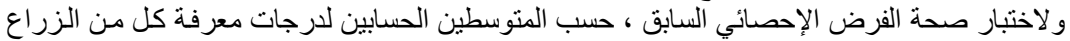

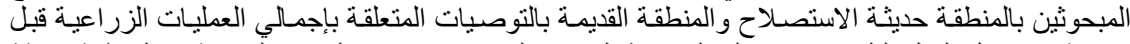

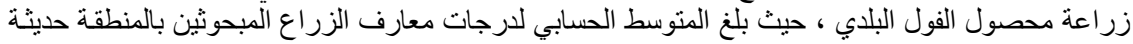

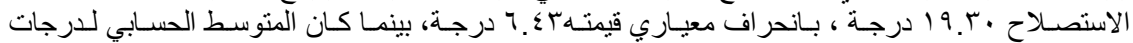

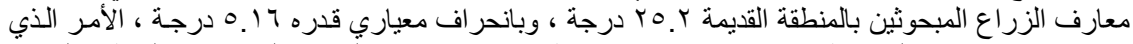

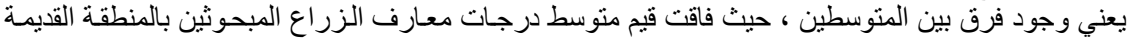

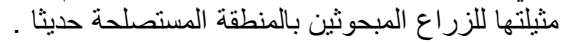

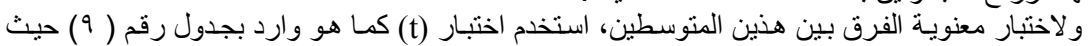

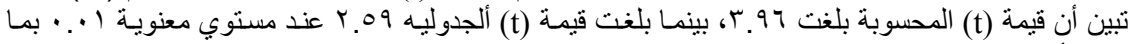

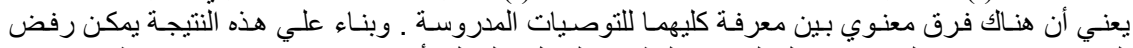

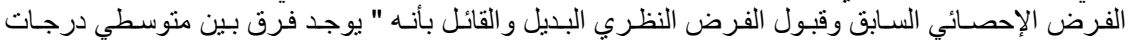

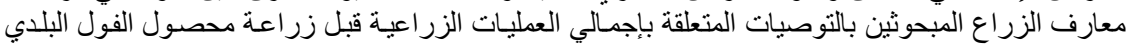

بكل من المنطقة الحديثة الاستصلاح و المنطقة القديمة " . 


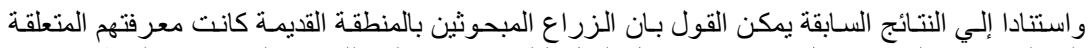

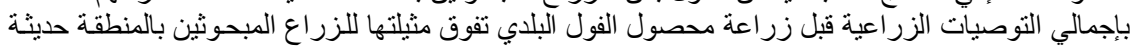

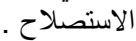

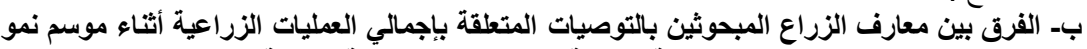

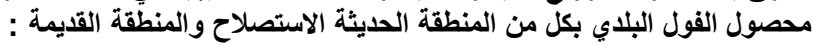

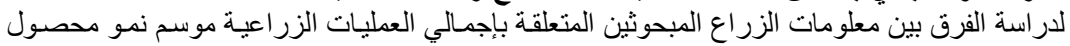

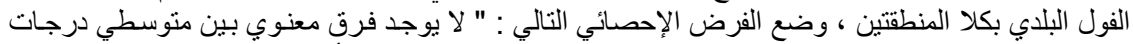

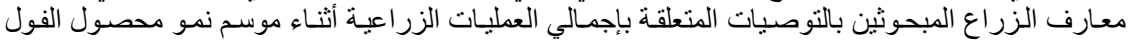

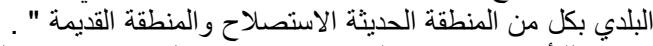

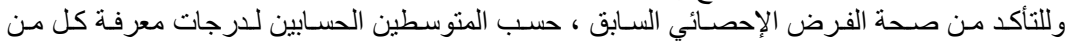

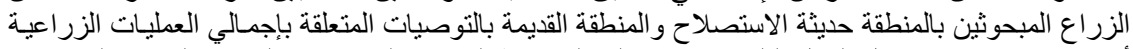

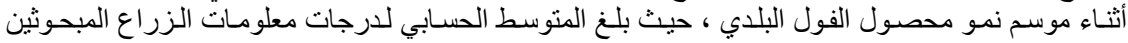

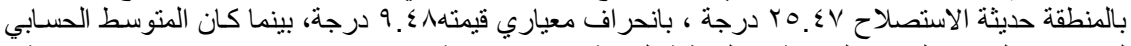

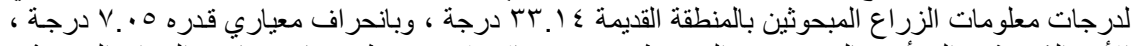

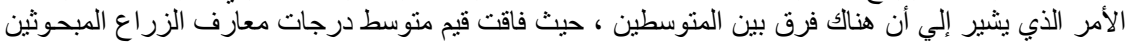

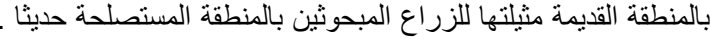

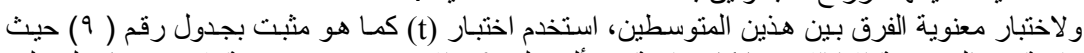

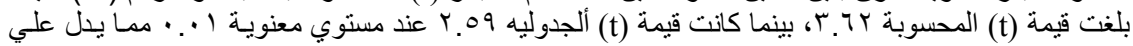

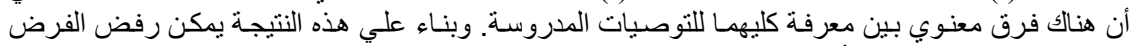

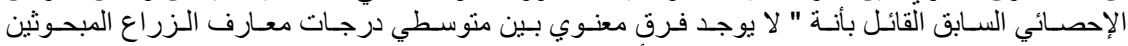

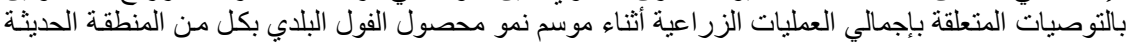

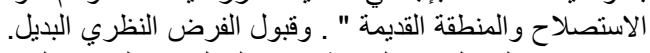

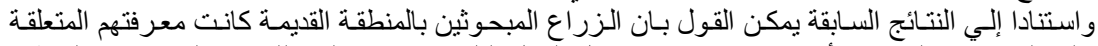

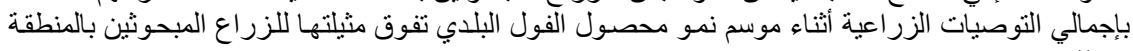
حديثة الاستصلاح

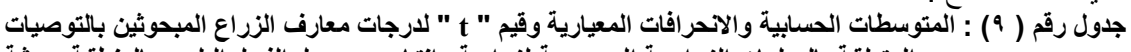

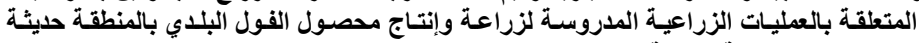

\begin{tabular}{|c|c|c|c|c|c|c|}
\hline \multirow{3}{*}{ قالمحسوبة } & & & & & & \\
\hline & \multicolumn{2}{|c|}{ 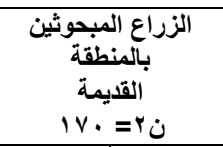 } & \multicolumn{2}{|c|}{ 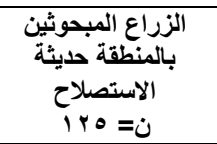 } & \multirow[t]{2}{*}{ 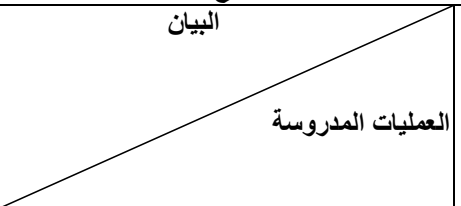 } & \\
\hline & المعياري الافي & المتوسط & المعياري الافي & المتوسط & & \\
\hline$* \star Y .97$ & 0.17 & ro.r. & $7 . \leqslant T$ & $19 . r$ & |العمليات الزر اعية قبل زر اعة المحصول & -1 \\
\hline$* * \pi . \pi$ & $v . .0$ & r.I. & $9 . \leqslant \wedge$ & $r_{0} \leqslant v$ & العمليات الزر اعية أثناء موسم نمو المحصول & $-r$ \\
\hline$* * r . \vee \wedge$ & $7 . \leqslant \wedge$ & rᄉ. .01 & $\Lambda . r v$ & r. & 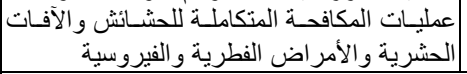 & $-r$ \\
\hline$* * 4 . \cdot 1$ & rT.VT & 97.94 & r৭.Ar & $\mathrm{VI} . \mathrm{IV}$ & ب العمليات المتعلقة بإنتاج وزر اعة المحصول & إجما \\
\hline
\end{tabular}

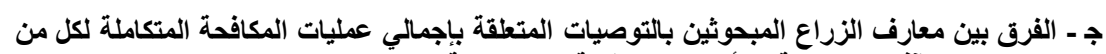

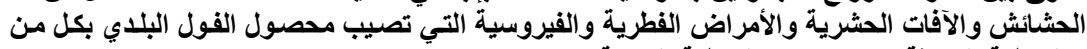

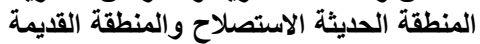

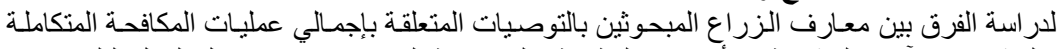

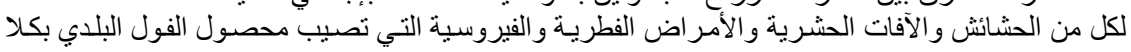

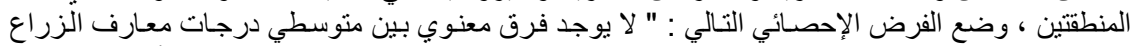

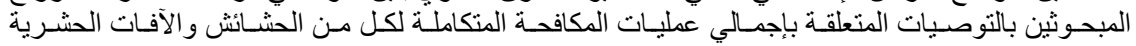


و الأمـر اض الفطريـة و الفيروسية التي تصـيب محصـول الفول البلدي بكل مـن المنطقة الحديثة الاستصـلاح و المنطقة القديمة " .

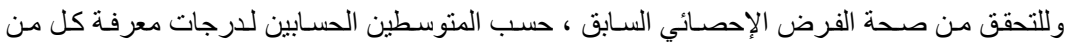

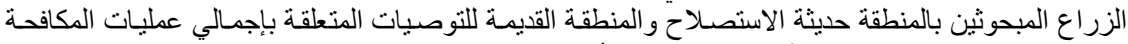

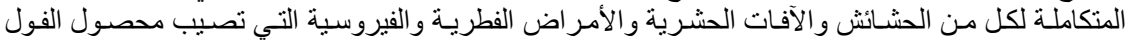

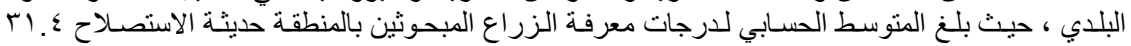

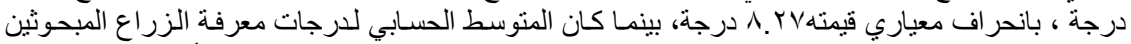

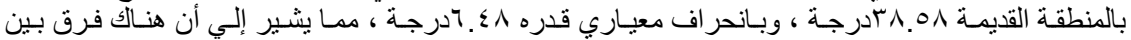

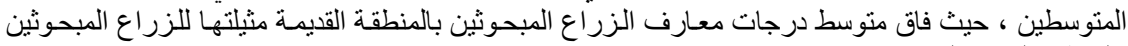

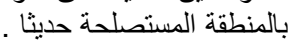

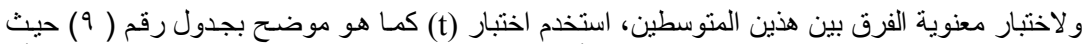

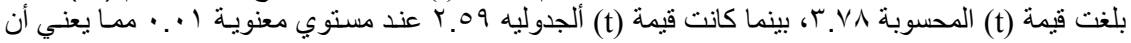

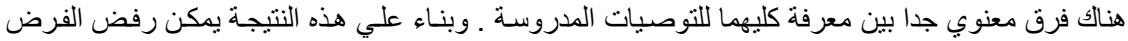

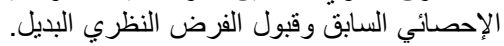

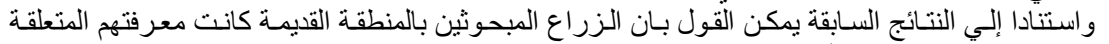

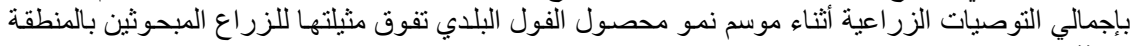

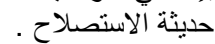
دـ - الفرق بين معارف الزئن الزراع المبحوثين بالتوصيات المتعقة بإجمالي عمليات زراعة وإنتاج محصول الفول

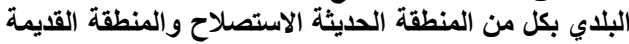

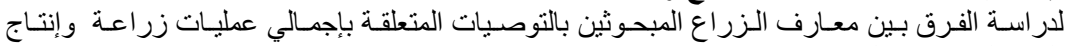

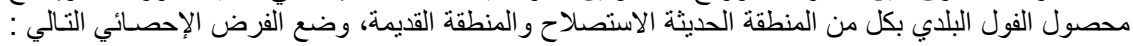

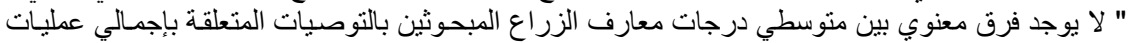

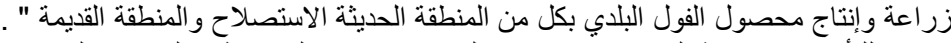

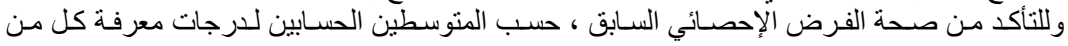

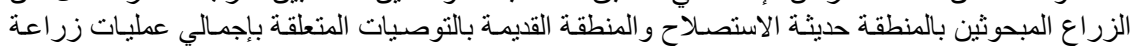

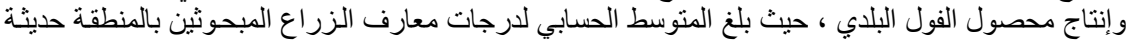

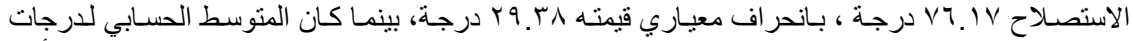

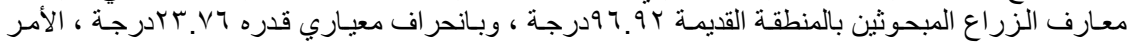

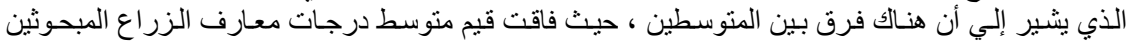

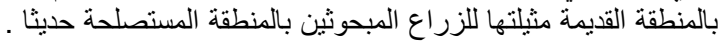

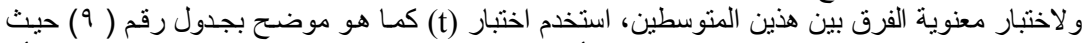

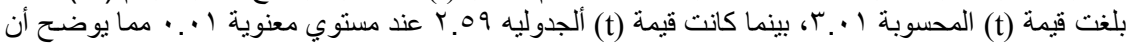

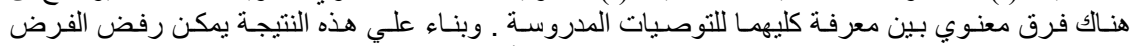

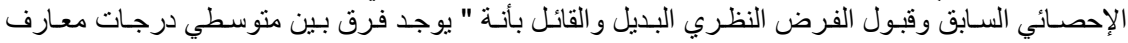

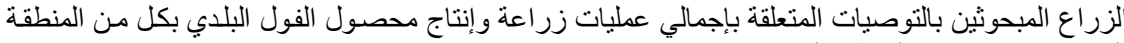

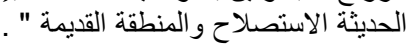

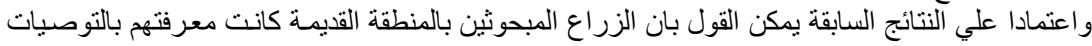

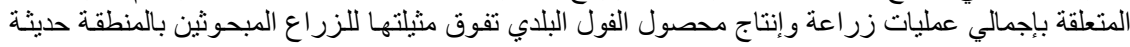

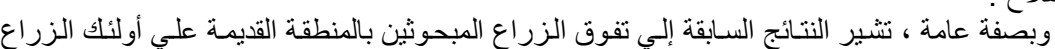
الاستصلاح

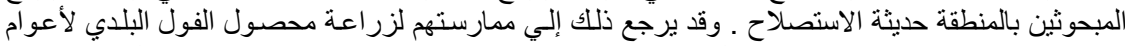

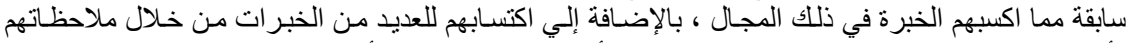

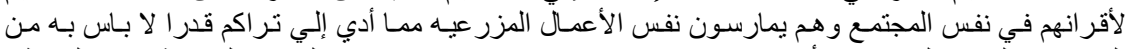

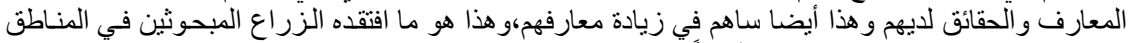

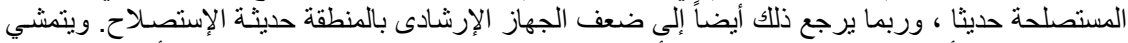

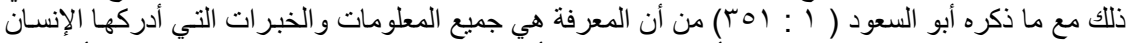

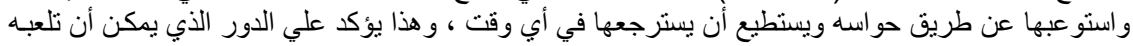




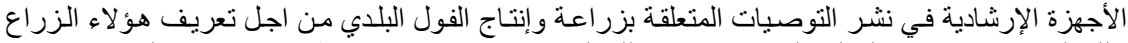

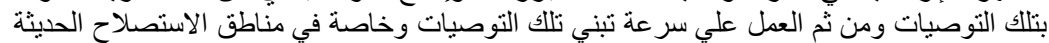

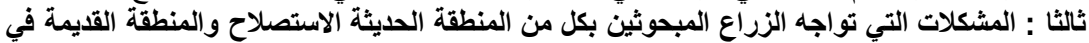

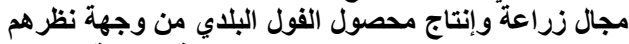

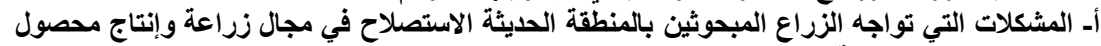

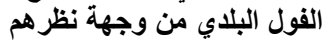

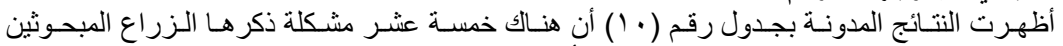

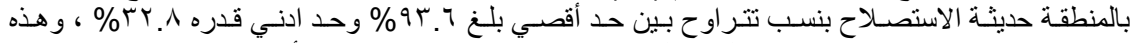

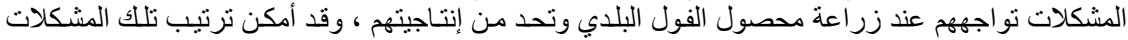

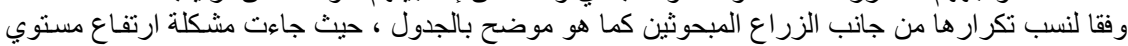

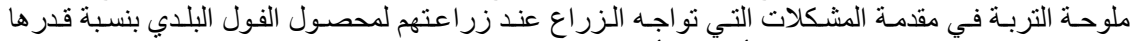

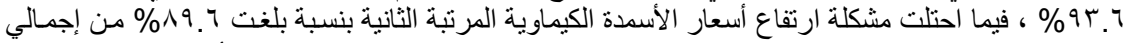

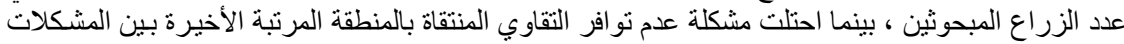

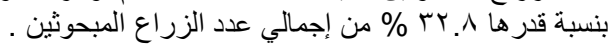

جلول رقم ( • 1) التكرارات والنسب المئوية للزراع المبحوثين بالمنطقة الحيثة الاستصلاح وفقا للمثكلات

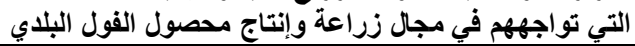

\begin{tabular}{|c|c|c|c|}
\hline \multicolumn{2}{|c|}{ زراع المناطق المستصلحة حديثا } & \multirow{2}{*}{ المشكلات البيان } & \multirow[t]{2}{*}{ s } \\
\hline$\%$ & عدد & & \\
\hline 94.7 & $11 \mathrm{~V}$ & |رتفاع مستوي ملوحة التربة & -1 \\
\hline 19.7 & $11 \mathrm{r}$ & |رتفاع أسعار "الأسدة الكيماوية & $-r$ \\
\hline$\wedge \cdot$. & 1.1 & سوء حالة الصرف الزراعي & $-r$ \\
\hline$V \leqslant . \varepsilon$ & 94 & |رتفاع أسعار العمالة الزر اعية & $-\varepsilon$ \\
\hline 79.7 & $\wedge \vee$ & ارتفاع أسعار المبيدات ل " & -0 \\
\hline $7 \varepsilon$. & $\wedge$. & قلة النشرات الإرشادية الخاصة بالمناطق المستصلحة & -7 \\
\hline $7 \cdot .1$ & $v_{7}$ & عدم إقامة ندوات إرشادية متعلقة بالمحصول & $-V$ \\
\hline 07.1 & vi & قلة أُعداد المرشدين الزرَاعيين بالمنطقة & $-\wedge$ \\
\hline 07.1 & $v_{1}$ & عدم تو افر أنو اع معينة من الأسمدة أثناء موسم النمو & -9 \\
\hline or.A & 77 & قلة مياه الري بالمنطقة & -1 . \\
\hline$\varepsilon V . r$ & 09 & ارتفاع أسعار التقاوي & -11 \\
\hline$\varepsilon r .4$ & $0 \leqslant$ & عدم تو افر المبيدات ألفعالة بالمنطقة & -14 \\
\hline rq. & $\leqslant 9$ & انخفاض سعر بيع الإردب في السوق & -14 \\
\hline rq. & $\leqslant 9$ & ضعف خصوبة التنربة & $-1 \leq$ \\
\hline r.^. & $\varepsilon 1$ & عدم تو افر التقاوي المنتقاة بالمنطقة & -10 \\
\hline
\end{tabular}


بـ المشكلات التي تواجه الزراع المبحوثين بالمنطقة القديمة في مجال زراعة وإنتاج محصول الفول

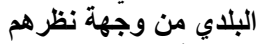

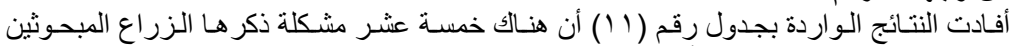

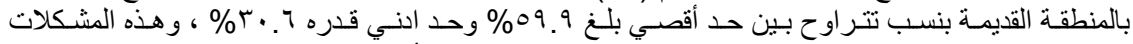

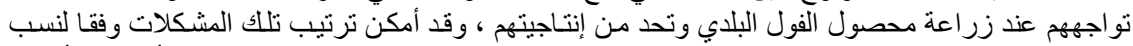

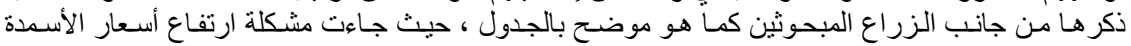

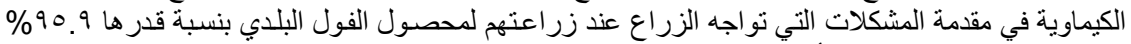

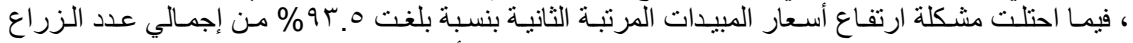

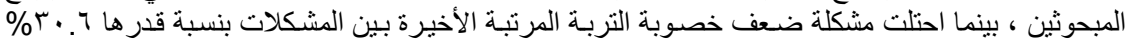

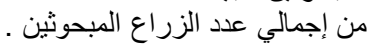

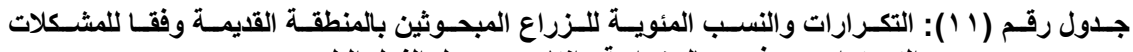

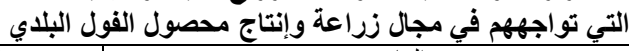

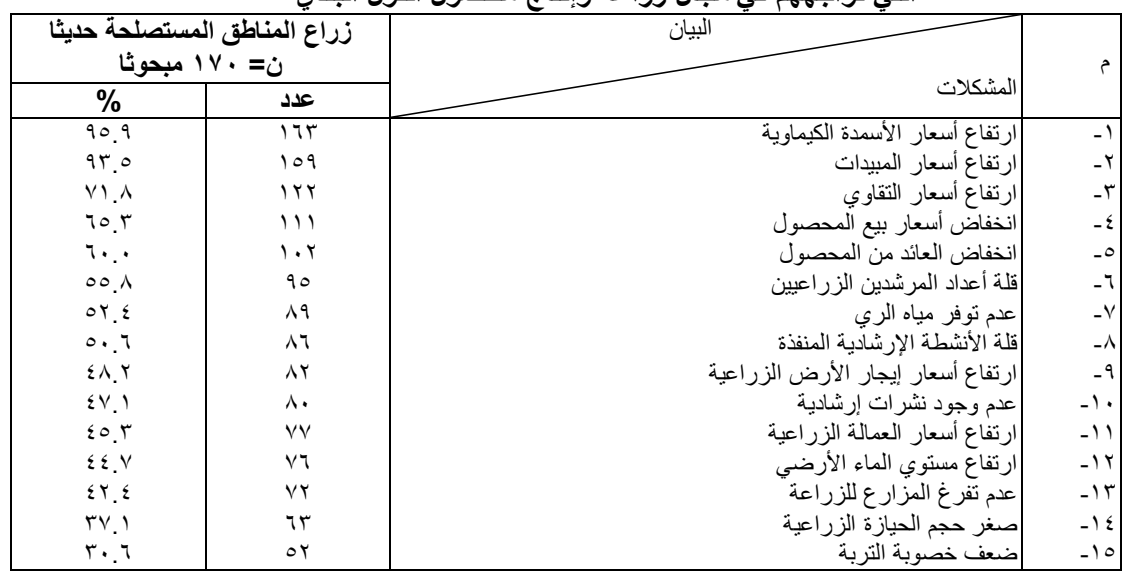

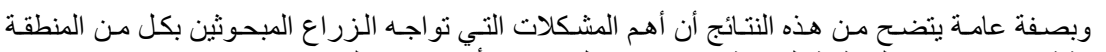

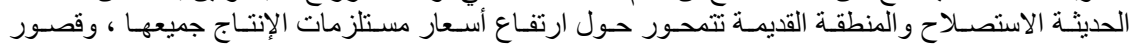

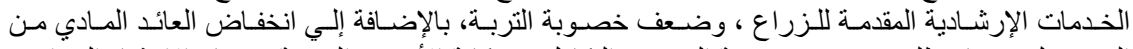

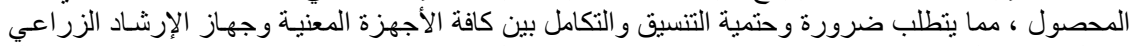

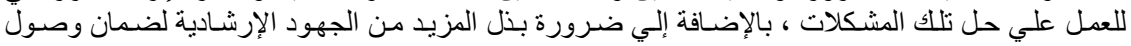

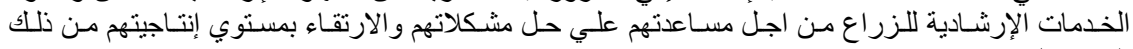

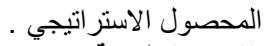
في ضوء ما أسفرت عنه نتائج هذا البحث يمكن التوصية بالاتي : الفوائد التطبيقية

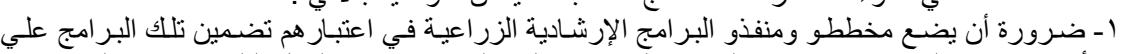

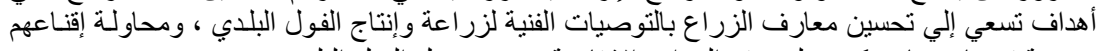

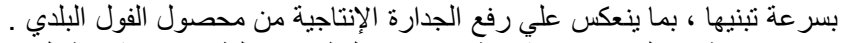

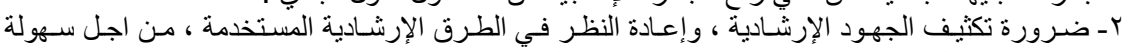

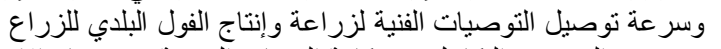

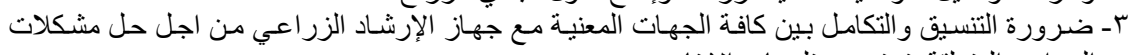

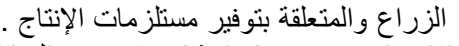
ـ ـ-الاهتمام بنوفير جهاز إرشادى قوى في المناطق حديثة الإستصلاح . المراجع (الاجع 


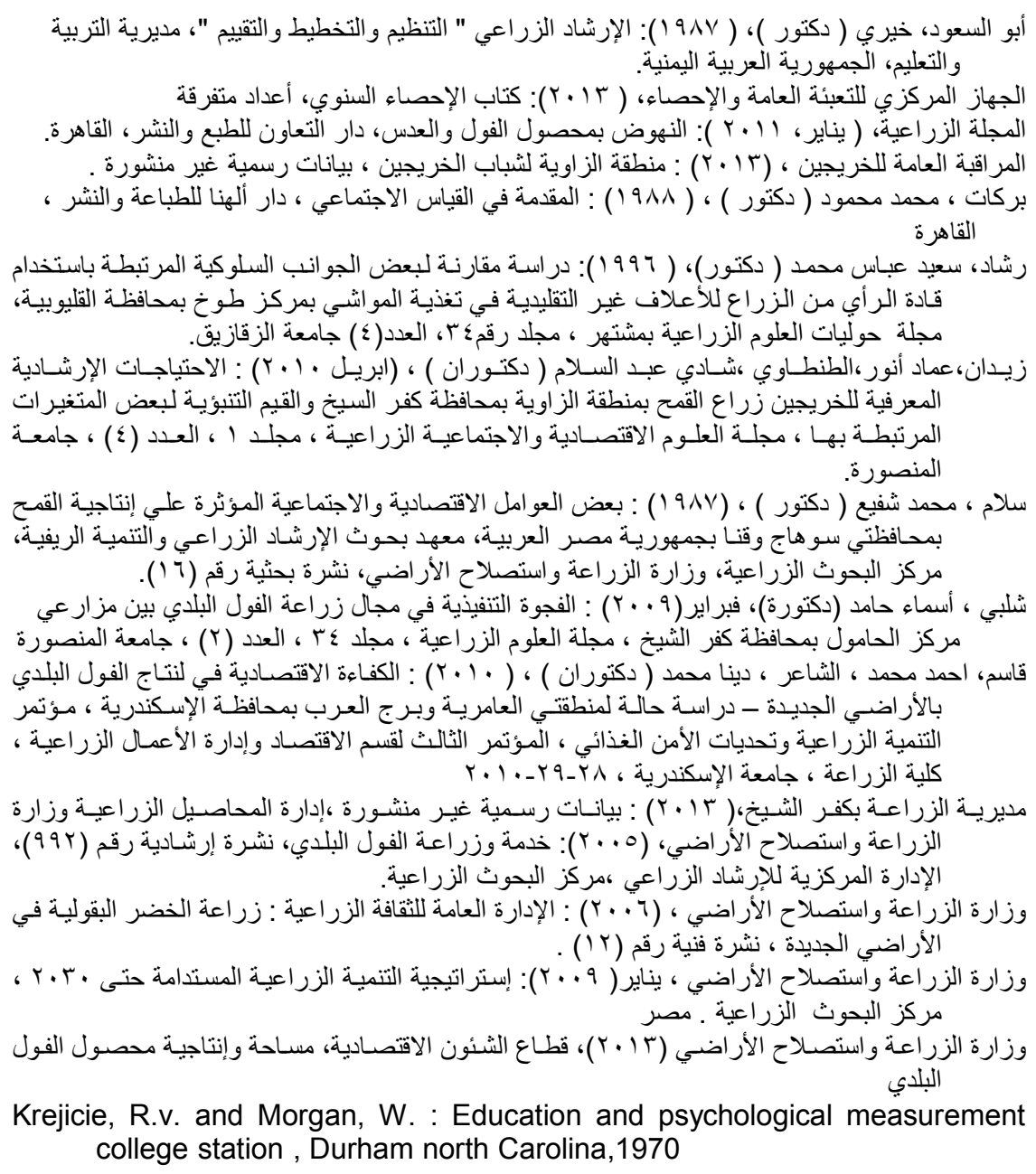

Krejicie, R.v. and Morgan, W. : Education and psychological measurement college station, Durham north Carolina,1970 


\title{
FARMERS KNOWLEDGE OF TECHNICAL RECOMMENDATIONS RELATED TO CULTIVATION AND PRODUCTION OF FABA BEAN IN NEWLY RECLAIMED AREA AND OTHER OLD AREA IN KAFR EL-SHEIKH GOVERNORAT
}

Zedan, E. A. A

Res. Inst. of Agric. Extension and Rural Development, Agric. Res. Center, Ministry of Agric. and Land Rreclamation

\begin{abstract}
knowledge

This research aimed mainly identify the farmers knowledge level of technical recommendations related to cultivation and production of faba bean in newly reclaimed area and other old area, And that by identifying the level of knowledge for each of the agricultural operations before growing the crop, farming operations during the season of growth, integrated for each of grass insect pests and diseases that afflict the crop fungal, viral, thoughtful and total Processes studied, in The study zones, , And then determine the differences between the farmers of both regions with respect to their knowledge of a total of each of the groups studied and studied the total operations, as well as to identify the problems faced by farmers in both region.

To achieve the objectives of this study were selected randomly six villages, three of them from the center Hamou of the governorate of Kafr ElSheikh to represent the area of the old farming villages they are: El-Kaf ElSharky, El- Abadia El- baharia and El- Banna, and three other villages of the El -Zawea area of the governorate of Kafr El-Sheikh to represent the area newly reclaimed They villages are : Qadisiyah, Mustafa, and Teba ,were selected randomly from the sample between the two regions, and by Using the equation Krijicie \& Morgan totaled 295 respondents surveyed by 170 respondents from villages center Hamoul and 125 respondents from villages El -Zawea area. The study collected data in a way the interview of the respondents growers, by means of a questionnaire was developed and tested initially so that the valid data collection, which was during the months of May and June 2013. The statements have been presented in the tables of loops with percentages, and were used in the statistical analysis of the difference between the test medium (t), and the arithmetic mean, and standard deviation.

The most important results are summarized as follows:

1 - the relative decline in the knowledge of the farmers surveyed zones, study the information relating to each of the processes agricultural crop before planting, agricultural operations during the growing season, the operations of integrated pest management for each of the weeds, insect pests, fungal and viral diseases that infect the crop, and the total operations studied.
\end{abstract}


2-The presence of significant differences between respondents and agricultural knowledge relating to each of the agricultural operations before planting crop, and agricultural operations during the growing season, and the operations of integrated pest management for each of the weeds and pests insect and fungal and viral diseases that infect the crop, and the total operations studied zones study.knowledge

3 - farmers knowledge surveyed in the region of old and relating to each of the agricultural operations before planting the crop agricultural operations during the growing season, the operations of integrated pest management for each of the weeds, insect pests and fungal and viral diseases that infect the crop, Total and thoughtful processes outweigh the counterpart of the growers surveyed the area newly reclaimed.

4 - among the most important problems facing the farmers surveyed in the region newly reclaimed are: high levels of soil salinity, rising prices of chemical fertilizers, poor drainage, high prices of agricultural employment, rising prices of pesticides, the lack of releases guidelines for the areas reclaimed, and failure to establish guidelines related seminars crop region.

5 - among the most important problems facing the farmers surveyed in the region is the old: the high price of chemical fertilizers, high prices of pesticides, the high price of seeds low selling prices of the crop, the lower the yield of the crop the small number of agricultural extension workers, and the lack of irrigation water.

كلية الزراعة - جامعة المنصورة كلية الزراعة - جامعة كفر الثيخ
قام بتحكيم البحث

أ.د / ابراهيم ابو خليل سعفان إندين

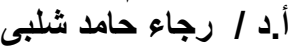

